\title{
Improving Therapeutic Potential of Farnesylthiosalicylic Acid: Tumor Specific Delivery via Conjugation with Heptamethine Cyanine Dye
}

\author{
Yang Guan ${ }^{\dagger} \ddagger$, Yi Zhang ${ }^{\dagger} \S$, Li Xiao $^{\dagger}$, Jie Li ${ }^{\dagger}, \|$, Ji-ping Wang ${ }^{\perp}$, Mahendra D. Chordia ${ }^{\dagger}$, Zhong- \\ Qiu Liü ${ }^{\ddagger}, \perp$, Leland W. K. Chung $§$, Wei Yue ${ }^{*}, \perp$, and Dongfeng Pan ${ }^{*} \dagger$ \\ tDepartment of Radiology and Medical Imaging, University of Virginia, Charlottesville, Virginia \\ 22903, United States \\ ${ }^{\perp}$ Department of Endocrinology, University of Virginia, Charlottesville, Virginia 22903, United \\ States \\ FInternational Institute for Translational Chinese Medicine, Guangzhou University of Chinese \\ Medicine, Guangzhou 51006, China \\ §Uro-Oncology Research Program, Department of Medicine, Cedars-Sinai Medical Center, Los \\ Angeles, California 90048, United States \\ "School of Materials Science \& Engineering, Beijing Institute of Technology, Beijing 100081, China
}

\section{Abstract}

The RAS and mTOR inhibitor $S$-trans-trans-farnesylthiosalicylic acid (FTS) is a promising anticancer agent with moderate potency, currently undergoing clinical trials as a chemotherapeutic agent. FTS has displayed its potential against a variety of cancers including endocrine resistant breast cancer. However, the poor pharmacokinetics profile attributed to its high hydrophobicity is a major hindrance for its continued advancement in clinic. One of the ways to improve its therapeutic potential would be to enhance its bioavailability to cancer tissue by developing a method for targeted delivery. In the current study, FTS was conjugated with the cancer-targeting heptamethine cyanine dye $\mathbf{5}$ to form the FTS-dye conjugate 11. The efficiency of tumor targeting properties of conjugate 11 against cancer cell growth and mTOR inhibition was evaluated in vitro in comparison with parent FTS. Cancer targeting of $\mathbf{1 1}$ in a live mouse model of MCF7 xenografts was demonstrated with noninvasive, near-infrared fluorescence (NIRF) imaging. The results from our studies clearly suggest that the bioavailability of FTS is indeed improved as indicated by $\log P$ values and cancer cell uptake. The FTS-dye conjugate 11 displayed higher potency $\left(\mathrm{IC}_{50}=16.8\right.$ $\pm 0.5 \mu \mathrm{M})$ than parent FTS $\left(\mathrm{IC}_{50}=\sim 51.3 \pm 1.8 \mu \mathrm{M}\right)$ and inhibited mTOR activity in the cancer

\footnotetext{
*Corresponding Authors: D.P.: Department of Radiology and Medical Imaging, University of Virginia, Charlottesville, VA 22904. Tel: 434-243-2893. dp3r@virginia.edu.; W.Y.: Department of Medicine, Endocrinology and Metabolism, University of Virginia, Charlottesville, VA 22904. Tel: 434-924-0399.wy9c@virginia.edu.

Supporting Information

The Supporting Information is available free of charge on the ACS Publications website at DOI: 10.1021/acs.molpharmaceut.5b00906. Spectroscopic data, cell assay figure, organ distribution of dye, NIRF imaging, experimental procedures, and HPLC analysis (PDF)

Notes

The authors declare no competing financial interest.
} 
cells at a lower concentration $(12.5 \mu \mathrm{M})$. The conjugate $\mathbf{1 1}$ was shown to be specifically accumulated in tumors as observed by in vivo NIRF imaging, organ distribution, and ex vivo tumor histology along with cellular level confocal microscopy. In conclusion, the conjugation of FTS with cancer-targeting heptamethine cyanine dye improved its pharmacological profile.

\section{Graphical abstract}

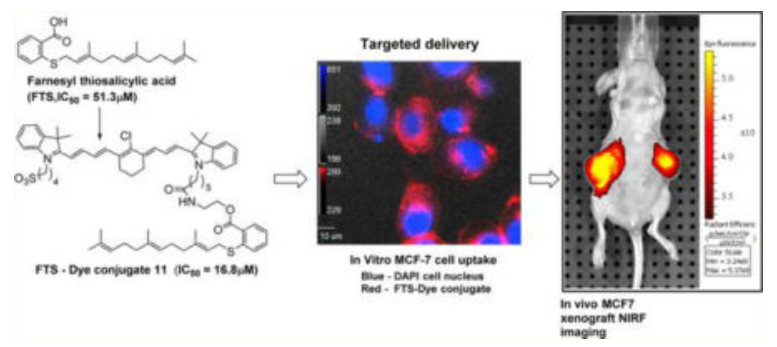

\section{Keywords}

Ras inhibitor; mTOR inhibitor; cancer targeting; drug delivery; breast cancer; farnesylthiosalicylic acid; heptamethine cyanine dye; NIRF imaging

\section{INTRODUCTION}

Targeted delivery of a chemotherapeutic agent to cancer cells is one of the most sought but highly challenging objectives in cancer chemotherapy. Developing a general delivery system which can carry a variety of therapeutic payloads selectively to cancer cells not only would improve therapeutic efficacy of the candidate drug molecule but also would minimize the side effects caused by chemotherapy due to nonspecific distribution in normal tissues. Many strategies toward this goal have been examined and utilized in practice for anticancer drug delivery. These include but are not limited to macromolecular delivery systems, such as liposomes,,${ }^{1-4}$ nanoparticles, ${ }^{5-8}$ or peptidomimetic/antibody conjugation. ${ }^{9}$ However, from a practical point of view it remains a major hurdle to design and standardize pharmacological properties and to optimize a macromolecular system, which is stable enough to load a precise amount of drug for delivery. The goal of such macromolecular assembly is to allow it to efficiently carry the payload by crossing various physiological barriers to reach the tumor tissues and to release the desired concentration as required. In a majority of methods the goal is mechanistically achieved by enhanced cell growth and leaky but dense tumor vasculature, and to a certain extent by targeting cell surface markers with antibodies ${ }^{10,11}$ In this regard, utilizing a cancer-targeting small molecule as a carrier to deliver therapeutic agents appears to be an attractive approach. We and others have recently demonstrated that certain types of heptamethine cyanine dyes have preferential abilities to target cancer cells when compared with their normal cell counterparts and have the ability to accumulate in the tumors. ${ }^{12-15}$ This preferential uptake of a heptamethine cyanine moiety in tumor is shown to be correlated with enhanced expression of certain types of organic anion transport peptide (OATP) in a variety of cancer cell types, ${ }^{15}$ and the hypoxic microenvironment of tumor. ${ }^{16,17}$ Targeted delivery of variants of theranostic agents to tumor by conjugation with heptamethine cyanine dye MHI-148 has been recently demonstrated. ${ }^{13,16}$ In order to 
improve the therapeutic potential of promising RAS and mTOR inhibitor $S$-trans-transfarnesylthiosalicylic acid (FTS) as an effective anticancer agent, conjugation with optimized heptamethine cyanine dye $\mathbf{5}$ was investigated in the current studies.

FTS is a relatively nontoxic but poorly bioavailable small molecule, currently undergoing phase II clinical trials for pancreatic cancer and lung adenocarcinoma. ${ }^{18,19}$ It has exhibited a high potential to be an effective chemotherapeutic drug due to selective targeting of intracellular signaling proteins. FTS is a first-in-class Ras inhibitor that suppresses cell growth by dislodging Ras anchoring in the cellular membrane. Mutated Ras proteins are constitutively active in numerous cancer types, for example, in pancreatic cancer ( $90 \%)$ and in colon cancer $(\sim 50 \%)$ of human cancers. ${ }^{20,21}$ Animals bearing a wide variety of established cancers and treated with FTS undergo a significant reduction of Ras levels with minimal observable side effects that are often associated with other cytotoxic anticancer agents. ${ }^{23}$ In addition to Ras inhibition we reported for the first time that FTS also inhibits mTOR as an alternative mechanism to suppress cancer cell growth and proliferation especially in endocrine resistant breast cancer cells. ${ }^{22}$ mTOR inhibition by FTS is independent of RAS inhibition, and it induces apoptosis in an endocrine resistant breast cancer model consisting of long-term estrogen deprived cells (LTED), therefore suggesting innovative means for treating endocrine resistant, relapsed breast cancer. ${ }^{23,24}$

The clinical development of FTS as an anticancer agent is hindered by its poor water solubility and unsuitable formulations. Attempts to improve FTS bioavailability by PEGylation have been shown to improve its solubility and therapeutic effects. ${ }^{25} \mathrm{~A}$ recent report on targeted delivery of FTS along with curcumin to tumor further emphasizes the need for a well-defined system to overcome pharmacological hurdles. ${ }^{26}$ In the present work the FTS-dye conjugate was synthesized and characterized, and its anticancer activity profile in terms of in vitro cancer cell specific uptake, inhibition of cell growth, mTOR inhibition, and in vivo cancer cell specific delivery by near-infrared fluorescence imaging was evaluated. The anticancer activity of the FTS-dye conjugate in the endocrine resistant breast cancer cell line, LTED, is demonstrated in comparison with the benign breast epithelial cell line, MCF-10A, as a control.

\section{EXPERIMENTAL PROCEDURES}

\section{Chemicals and Instruments}

IR 783 (6) was purchased for comparison from Sigma Chemicals (Saint Louis, MO). MHI-148 (7) for the current studies was synthesized as reported earlier. ${ }^{12,27}$ Cyanine-7 (Cy-7, 8) was purchased from GE Healthcare Life-Sciences (Pittsburgh, PA). All other chemicals and reagents were purchased from standard sources such as Sigma-Aldrich and/or Acros and were of the highest quality available. All procured chemicals were used as is since the products derived from them were purified and analyzed afterward. $4^{\prime}, 6$ Diamidino-2-phenylindole (DAPI) as a fluorescent nuclear stain was procured from Thermo Scientific. FTS was gift from Concordia Pharmaceuticals (Ft. Lauderdale, FL). Deionized ultrapure water (resistivity, $18.2 \mathrm{M} \Omega \mathrm{cm}$ ) used for making solutions was obtained from a Milli-Q Direct Ultrapure Water System from Millipore (Billerica, MA, USA). All intermediates were primarily characterized by ${ }^{1} \mathrm{H}$ and ${ }^{13} \mathrm{C}$ NMR and mass analysis, and the 
purity of compounds was analyzed by HPLC. The analyses of commercially available dyes were performed by HPLC for homogeneity prior to their in vitro cell uptake studies. If required, they were purified by semiprep HPLC prior to use. ${ }^{1} \mathrm{H}$ NMR data were collected on Varian 300 or $500 \mathrm{MHz}$ spectrometers using standard parameters; chemical shifts are reported in $\operatorname{ppm}(\delta)$ in reference to residual nondeuterated solvent. Coupling constants are reported in Hz. Purification of the newly synthesized compounds were conducted on a preparative HPLC system consisting of a Varian Prostar system equipped with pumps, 210; column valve module, 500; fraction collector, 701; and a PDA detector (Palo Alto, CA) using DENALI 238 DE C18 SPRING preparative column $(120 \AA$, $250 \times 25 \mathrm{~mm})$ and/or an Alltech Apollo C18 semipreparative column $(5 \mu \mathrm{m}, 250 \times 10 \mathrm{~mm})$ with a Phenomenex C18 Security Guard cartridge system $(10 \times 10 \mathrm{~mm}$ i.d. $)$ (Grace Davison Discovery Sciences). Two mobile phases were used for HPLC: solvent A ( $0.1 \%$ TFA in water) and solvent B ( $0.1 \%$ TFA in $80 \%$ aqueous acetonitrile). The mobile phase gradient varied according to characteristics of compounds, and eluents were monitored at dual wavelengths 254 and 750 $\mathrm{nm}$ (a flow rate of $12 \mathrm{~mL} / \mathrm{min}$ for the preparative column and $3 \mathrm{~mL} / \mathrm{min}$ for the semipreparative column). For analytical HPLC, Alltech's Econosphere C18 reverse phase column $(3 \mu, 4.6 \mathrm{~mm}$ i.d. $\times 150 \mathrm{~mm})$ was used at flow rate of 0.5 or $1.0 \mathrm{~mL} / \mathrm{min}$ using a gradient of solvents A and B as mentioned above and monitored at $750 \mathrm{~nm}$. The details are reported for each compound in characterization data. Matrix-assisted laser desorption/ ionization time-of-flight mass spectroscopy (MALDI-TOF-MS) analysis was performed on new compounds at the W.M. Keck Biomedical Mass Spectrometry Laboratory using a Bruker Daltonics system at the University of Virginia. UV-vis spectra for dye and FTS conjugate were collected from the UV-vis spectrometer with a path length of $1 \mathrm{~cm}$ (Biomate 5, Thermo Spectronic, Rochester, NY) scanned from 300 to $900 \mathrm{~nm}$ and analyzed by VISIONlite software (Thermo Scientific). Molar extinction coefficients $(\varepsilon)$ were then calculated. Fluorescence emission spectra were acquired with a Horiba FluoroMax 4 spectrofluorometer (JOBIN YVON/HORIBA, Edison, NJ) with a variety of excitation wavelengths with slit width of $5 \mathrm{~nm}$ and integration time of $0.2 \mathrm{~s}$ for all measurements. Spectral data were recorded, processed, and plotted with Origin software (Origin Lab, Northampton, MA). Quantitative near-infrared fluorescence (optical) cell uptake studies were performed on a LI-COR instrument (LICOR Biotechnologies, Lincoln, NE), and the fluorescence data were obtained using $800 \mathrm{~nm}$ emission with standard parameters, and for particular studies all parameters were kept constant for acquiring fluorescence intensity and wherever necessary normalized to protein. The confocal microscopic imaging on tumor tissue as well as cancer cells for confirmation of uptake of heptamethine cyanine dyes was performed on an Olympus IX81 inverted microscope equipped with six-position fluorescence filter turret using Slidebook software (Version 6.0, Intelligent Imaging Innovations Inc., Denver, CO) for image collection and data processing.

\section{Synthesis and Characterization}

\section{Synthesis of [3-(Anilinomethylene)-2-chloro-1-cyclohexen-1-yl]ethenyl-5- carboxy-3,3-dimethyl-1-(4-sulfobutyl)-3H-indolium 3-Sodium acetate (975 mg,} $11.9 \mathrm{mmol})$ was added to a solution of $N$-[(3-(anilinomethylene)-2-chloro-1-cyclohexen-1yl)-methylene]aniline monohydrochloride $2(4.7 \mathrm{~g}, 13.0 \mathrm{mmol})$ and 4-(2,3,3-trimethyl-3 $\mathrm{H}$ indol-1-ium-1-yl)butane-1-sulfonate $1(3.5 \mathrm{~g}, 11.8 \mathrm{mmol})$ in $150 \mathrm{~mL}$ of anhydrous ethanol at 
room temperature. The reaction mixture was heated to reflux in an oil bath for $2 \mathrm{~h}$. The mixture was concentrated to $75 \mathrm{~mL}$ after heating under reduced pressure, and to it was added $100 \mathrm{~mL}$ of acetone. The mixture was left overnight for crystallization, the precipitate was collected next day, and the solid was washed with acetone and dried under vacuum to yield compound 3 (3.9 g, 63\%): ${ }^{28} \mathrm{HRMS}$ (ESI-TOF) calcd for $\mathrm{C}_{29} \mathrm{H}_{34} \mathrm{ClN}_{2} \mathrm{O}_{3} \mathrm{~S}[\mathrm{M}+\mathrm{H}]$ + 525.1979, found 525.1979; ${ }^{1} \mathrm{H}$ NMR (DMSO- $\left.d_{6}, 400 \mathrm{MHz}\right) \delta 10.20(\mathrm{~s}, 1 \mathrm{H}), 8.43(\mathrm{~d}, 1 \mathrm{H}, J$ $=16 \mathrm{~Hz}), 8.19(\mathrm{~s}, 1 \mathrm{H}), 7.71(\mathrm{~m}, 2 \mathrm{H}), 7.53-7.39(\mathrm{~m}, 6 \mathrm{H}), 7.16(\mathrm{~m}, 1 \mathrm{H}), 6.62(\mathrm{~d}, 1 \mathrm{H}, J=12$ $\mathrm{Hz}), 4.38(\mathrm{~m}, 2 \mathrm{H}), 2.71(\mathrm{~m}, 4 \mathrm{H}), 2.52(\mathrm{~m}, 2 \mathrm{H}), 1.87(\mathrm{~m}, 4 \mathrm{H}), 1.75(\mathrm{~m}, 2 \mathrm{H}), 1.69(\mathrm{~s}, 6 \mathrm{H})$.

\section{Synthesis of 3H-Indolium, 2-[2-[3-[2-[1-(5-Carboxypentyl)-1,3-dihydro-3,3- dimethyl-2H-indol-2-ylidene]ethylidene]-2-chloro-1-cyclohexen-1- yl]ethenyl]-3,3-dimethyl-1-(4-sulfobutyl) Inner Salt 5-Compound 3 (2.0 g, 3.8} mmol) was heated with 4 [(3H-indolium, 1-(5-carboxypentyl)-2,3,3-trimethyl-bromide] $(1.35 \mathrm{~g}, 3.8 \mathrm{mmol})^{29,30}$ in the presence of sodium acetate $(313 \mathrm{mg}, 3.8 \mathrm{mmol})$ in $100 \mathrm{~mL}$ of ethanol to reflux for $2 \mathrm{~h}$. The reaction mixture was concentrated to $50 \mathrm{~mL}$ under reduced pressure, and $100 \mathrm{~mL}$ of diethyl ether was added. The solid was collected and crystallized from ethanol-water to give a dark green solid (1.7 g, 63\%, 95\% pure). HPLC analysis (70\%-100\% solvent B in $30 \mathrm{~min}$ ) exhibited a peak with a retention time of $11.4 \mathrm{~min}$. Two other minor compounds formed in the reaction remained in the filtrate, and TLC and HPLC analysis suggested them to be two known compounds, IR-783 (6) (most polar) and MHI-148 (7). Characterization data for compound 5: HRMS (ESI-TOF) calcd for $\mathrm{C}_{40} \mathrm{H}_{50} \mathrm{ClN}_{2} \mathrm{O}_{5} \mathrm{~S}$ [M $+\mathrm{H}]$ 705.3129, found 705.3122; ${ }^{1} \mathrm{H}$ NMR (400 MHz, DMSO- $\left.d_{6}\right) \delta 8.24(\mathrm{~d}, J=15.0 \mathrm{~Hz}$, 2H), 7.59 (d, $J=5.0 \mathrm{~Hz}, 2 \mathrm{H}), 7.40-7.47(\mathrm{~m}, 4 \mathrm{H}), 7.25,(\mathrm{t}, J=5.0 \mathrm{~Hz}, 2 \mathrm{H}), 6.35$ (d, $J=15.0$ $\mathrm{Hz}, 1 \mathrm{H}), 5.66$ (brs, 1H), 4.20 (brs, 4H), 2.70 (m, 4H), 2.67 (brt, 4H), 1.67-1.87 (m, 13H), 1.64 (brs, 12H).

Synthesis of Cyanine Dye 10-Compound 5 (226 mg, $0.32 \mathrm{mmol}$ ) was mixed with dicyclohexylcarbodiimide (DCC, $75 \mathrm{mg}, 0.364 \mathrm{mmol}$ ) and $\mathrm{N}$-hydroxy succinamide (40 $\mathrm{mg}$, $0.35 \mathrm{mmol}$ ) in methylene chloride and stirred at room temperature overnight to activate carboxylic acid to its $N$-hydroxy ester. On the next day the reaction mixture was filtered to remove solid byproduct, dicyclohexylurea, the filtrate was concentrated and triturated with ether, the ethereal layer was removed, and the leftover solid (244 mg) was collected and used without purification for the next reaction. The solid was dissolved in $2.5 \mathrm{~mL}$ of dry DMF, ethanol amine (25 $\mathrm{mg}, 0.41 \mathrm{mmol}$ ) was added to the solution, and the mixture was stirred at room temperature for $3 \mathrm{~h}$. The solution was diluted with ether $(25 \mathrm{~mL})$ to remove as much DMF as possible, and the leftover residue was purified with Combiflash column chromatography (Teledyne Isco, Lincoln, NE) over silica gel (RediSep 12 g, ethyl acetate:methanol 98:2) to afford ethanol amide 10 (187 mg, 78\% overall two step yield) and was characterized by ${ }^{1} \mathrm{H}$ NMR and mass analysis: MS (MALDI-TOF) HRMS (ESI-TOF) calcd for $\mathrm{C}_{42} \mathrm{H}_{55} \mathrm{ClN}_{3} \mathrm{O}_{5} \mathrm{~S}[\mathrm{M}+\mathrm{H}]+748.3551$, observed 748.3548. ${ }^{1} \mathrm{H}$ NMR $(300 \mathrm{MHz}$, DMSO- $\left.d_{6}\right) \delta 8.26(\mathrm{t}, J=15.0 \mathrm{~Hz}, 2 \mathrm{H}), 7.78(\mathrm{t}, J=6.0 \mathrm{~Hz}, 1 \mathrm{H}), 7.63(\mathrm{t}, J=6.0 \mathrm{~Hz}, 2 \mathrm{H}), 7.53$ $(\mathrm{d}, J=9.0 \mathrm{~Hz}, 1 \mathrm{H}), 7.39-7.48(\mathrm{~m}, 2 \mathrm{H}), 7.22-7.35(\mathrm{~m}, 2 \mathrm{H}), 6.43(\mathrm{~d}, J=15.0 \mathrm{~Hz}, 1 \mathrm{H}), 6.29$ $(\mathrm{d}, J=15.0 \mathrm{~Hz}, 1 \mathrm{H}), 4.14-4.30(\mathrm{~m}, 4 \mathrm{H}), 3.35(\mathrm{t}, J=6.0 \mathrm{~Hz}, 2 \mathrm{H}), 3.07(\mathrm{q}, J=6.0 \mathrm{~Hz}, 2 \mathrm{H})$, 2.62-2.78 (m, 4H), $2.06(\mathrm{t}, J=6.0 \mathrm{~Hz}, 2 \mathrm{H}), 1.75-1.91(\mathrm{~m}, 1 \mathrm{H}), 1.45-175(\mathrm{~m}, 2 \mathrm{H}), 1.66(\mathrm{~s}$, $6 \mathrm{H}), 1.25-1.42(\mathrm{~m}, 2 \mathrm{H})$; partial ${ }^{13} \mathrm{C}$ NMR (75 MHz, DMSO- $\left.d_{6}\right) \delta 172.8,172.6,172.2$, 
$171.9,159.2,158.8,158.2,157.7,148.1,143.5,142.7,142.1,141.2,141.0,128.7,126.5$, 126.2, 125.3, 122.5, 121.0, 117.1, 113.3, 111.8, 111.4, 102.1, 101.4, 67.2, 60.1, 50.7, 49.0, $43.9,41.5,37.0,35.1,33.4,27.5,27.4,25.88,25.0,22.4,20.5$.

Synthesis of FTS-Dye Conjugate 11-The alcohol-dye 10 (78 $\mathrm{mg}, 0.104 \mathrm{mmol})$ and FTS (45 mg, $0.125 \mathrm{mmol}$ ) were dissolved in DMF at room temperature; to this mixture was added EDC ( $24 \mathrm{mg}, 0.125 \mathrm{mmol})$ followed by DMAP $(1.3 \mathrm{mg}, 0.01 \mathrm{mmol})$, and the mixture was stirred at room temperature overnight $(\sim 12 \mathrm{~h})$. The HPLC analysis indicated formation of a new nonpolar compound. The reaction mixture was crashed out in ether to remove the DMF, leftover residue was dissolved in methanol and subjected to further purification by semi-preparative HPLC (60\%-100\% solvent B in 30 min, monitored both at 254 and 750 $\mathrm{nm}$ ), and fractions were collected for the peak with retention time $12.3 \mathrm{~min}$. The all homogeneous fractions (single peak) were combined and concentrated under reduced pressure. The leftover pure solid was crystallized from methanol:ether to obtain solid (55 $\mathrm{mg}, 55 \%$ yield). The analytical HPLC indicated it to be a single homogeneous compound under varying mobile phase conditions: HRMS (ESI-TOF) calcd for $\mathrm{C}_{64} \mathrm{H}_{83} \mathrm{ClN}_{3} \mathrm{O}_{6} \mathrm{~S}_{2}[\mathrm{M}+$ $\mathrm{H}]^{+}$1088.5411, observed 1088.5408; ${ }^{1} \mathrm{H}$ NMR (500 MHz, DMSO- $\left.d_{6}\right) \delta 8.28(\mathrm{~d}, J=15.0$ $\mathrm{Hz}, 1 \mathrm{H}), 8.24(\mathrm{~d}, J=15.0 \mathrm{~Hz}, 1 \mathrm{H}), 7.77(\mathrm{t}, J=5.0 \mathrm{~Hz}, 1 \mathrm{H}), 7.64(\mathrm{~d}, J=10.0 \mathrm{~Hz}, 1 \mathrm{H}), 7.62$ (d, $J=10.0 \mathrm{~Hz}, 1 \mathrm{H}), 7.52(\mathrm{~d}, J=9.0 \mathrm{~Hz}, 1 \mathrm{H}), 7.44(\mathrm{~d}, J=10.0 \mathrm{~Hz}, 1 \mathrm{H}), 7.42$ (brd, 2H), 7.30 (d, $J=, 1 \mathrm{H}), 7.20-729(\mathrm{~m}, 2 \mathrm{H}), 6.43(\mathrm{~d}, J=15.0 \mathrm{~Hz}, 1 \mathrm{H}), 6.29(\mathrm{~d}, J=15.0 \mathrm{~Hz}, 1 \mathrm{H}), 5.58(\mathrm{~d}$, $J=5.0 \mathrm{~Hz}, 1 \mathrm{H}$ ), $4.64(\mathrm{t}, J=5.0 \mathrm{~Hz}, 1 \mathrm{H}), 4.24$ (brt, $J=5.0 \mathrm{~Hz}, 1 \mathrm{H}), 4.18$ (brt, $J=5.0 \mathrm{~Hz}$, $1 \mathrm{H}), 3.35(\mathrm{t}, J=6.0 \mathrm{~Hz}, 2 \mathrm{H}), 3.07(\mathrm{q}, J=6.0 \mathrm{~Hz}, 2 \mathrm{H}), 2.62-278(\mathrm{~m}, 4 \mathrm{H}), 2.06(\mathrm{t}, J=6.0 \mathrm{~Hz}$, 2H), 1.75-191 (m, 1H), 1.45-175 (m, 2H), $1.66(\mathrm{~s}, 6 \mathrm{H}), 1.25-1.42(\mathrm{~m}, 2 \mathrm{H})$; partial ${ }^{13} \mathrm{C}$ NMR (125 MHz, DMSO- $\left.d_{6}\right) \delta 172.7,172.0,171.6,166.9,156.6,147.9,143.5,142.4,142.1$, 142.0, 141.2, 141.0, 128.6, 126.4, 125.3, 122.5, 111.9, 111.3, 102.3, 101.1, 95.1, 59.9, 50.6, $48.8,47.5,41.3,35.0,33.3,27.5,27.4,24.4,22.5,20.5$.

\section{UV-Vis and Fluorescence Spectroscopic Evaluation}

UV-Vis Spectra-Solutions ( $10 \mu \mathrm{M})$ of dyes 5-7 and FTS-dye conjugate 11 were prepared separately in $0.1 \mathrm{M}$ PBS buffer ( $\mathrm{pH} 7.45$ ) with $0.25 \%$ (v/v) DMSO and diluted to $1,05,0.1,0.05$, and $0.01 \mu \mathrm{M}$. UV-vis absorption measurements of each of solution were obtained in the range of 300-900 $\mathrm{nm}$ and acquired and processed by VISIONlite software. Molar extinction coefficients $(\varepsilon)$ were then calculated.

Fluorescence Spectra-Fluorescence emission spectra were obtained with a Horiba FluoroMax 4 spectrofluorometer (JOBIN YVON/HORIBA, Edison, NJ) with a variety of excitation wavelengths $(650,675,700,725,750$, and $775 \mathrm{~nm})$, with slit width of $5 \mathrm{~nm}$ and integration time of $0.2 \mathrm{~s}$ for all measurements. Stock solutions of $20 \mu \mathrm{M}$ each for all dyes (5, $\mathbf{6}, \mathbf{7}$, and $\mathbf{8}$ ) were prepared by dissolving solid sample in $97 \%$ aqueous solution with $\sim 3 \%$ DMSO. Fluorescence spectra were measured by adding $3 \mathrm{~mL}$ aliquots of the stock solutions into a quartz cuvette with $1 \mathrm{~cm}$ path length. Spectral data were recorded and processed; fluorescence intensities were normalized and plotted with Origin software. The concentration dependent $(0.15,0.7,3.5,7.0$, and $35 \mu \mathrm{M})$ fluorescence intensities were recorded for the hetero dye 5 . 
Partition Coefficient-The hydrophilicity of compounds $\mathbf{7 , 8}$, and $\mathbf{9}$ was determined by measuring the partition coefficient constant in $n$-octanol and water. In brief, the purified compound $(5 \mathrm{nmol})$ was dissolved in an equal volume $(0.6 \mathrm{~mL} / 0.6 \mathrm{~mL})$ mixture of $n$-octanol and deionized water, resulting in a final concentration of $4.15 \mu \mathrm{M}$ that was within the linear relationship range between fluorescence probe concentration and fluorescence intensity. After vigorous mixing for $10 \mathrm{~min}$, the mixture was centrifuged at 10,000 rpm for $5 \mathrm{~min}$. Aliquots (in triplets) of $100 \mu \mathrm{L}$ from each organic and aqueous layer were aspirated out carefully and transferred into a 96-well plate for fluorescence measurement individually. The 96-well plate was placed under the CCD camera of a Xenogen IVIS Spectrum (Caliper Life Sciences, Hopkinton, MA), and the fluorescence was measured with a filter set of Ex/Em = $745 / 820 \mathrm{~nm}$ (auto exposure, medium binning, $F$-stop $=2$ ). The fluorescence intensity of each well was measured by drawing regions of interest (ROIs) on the well boundaries and recorded as average radiance $\left(\mathrm{p} / \mathrm{s} / \mathrm{cm}^{2} / \mathrm{sr}\right)$ using software LiveImage 3.1. Partition coefficient parameter $\log P$ was calculated using the equation $\log$ ([fluorescence intensity in octanol]/ [fluorescence intensity in water]). Fluorescence intensities to calculate $\log P$ were first corrected for solvent effect. The coefficient factor was calculated based on variation in fluorescence intensities of the same concentration of each probe in $n$-octanol and water. The average and standard deviation of $\log P$ values were calculated.

\section{Biological Studies}

Cell Culture-MCF-7 cells (originally provided by Dr. R. Bruggemeier, The Ohio State University) were grown in IMEM containing 5\% fetal bovine serum (FBS) (Invitrogen) and $1 \%$ penicillin/streptomycin (GIBCO). ${ }^{31}$ MCF-10A cells are an immortalized, nontransformed epithelial cell line derived from human fibrocystic mammary tissue and were purchased from American Type Culture Collection (ATCC). MCF-10A cells were cultured in DMEM/F12 medium supplemented with epidermal growth factor $40 \mathrm{ng} / \mathrm{mL}$ (BioVision), insulin $10 \mu \mathrm{g} / \mathrm{mL}$ (Sigma), hydrocortisone $500 \mathrm{ng} / \mathrm{mL}$ (Sigma), cholera toxin $100 \mathrm{ng} / \mathrm{mL}$ (Calbiochem), 5\% horse serum (Invitrogen), and 1\% penicillin and streptomycin. Unless otherwise mentioned, all cell lines were cultured in the incubator at $37^{\circ} \mathrm{C}$ in a $5 \%$ $\mathrm{CO}_{2}$ humidified atmosphere $\left(\mathrm{CO}_{2}\right.$ water jacketed incubator, series II, Forma Scientific). Phosphate buffered saline (PBS) (0.1 M, pH 7.45) was purchased from Invitrogen. Human serum albumin (HSA) was procured from Sigma-Aldrich. Krebs-Henseleit (KH) buffer (118 $\mathrm{mM} \mathrm{NaCl}, 23.8 \mathrm{mM} \mathrm{NaHCO}_{3}, 4.83 \mathrm{mM} \mathrm{KCl}, 0.96 \mathrm{mM} \mathrm{KH}_{2} \mathrm{PO}_{4}, 1.20 \mathrm{mM} \mathrm{MgSO}{ }_{4}, 12.5$ mM HEPES, $5.0 \mathrm{mM}$ glucose, and $1.53 \mathrm{mM} \mathrm{CaCl}_{2}, \mathrm{pH}$ adjusted to 7.4) was prepared. LTED cells are derived from MCF-7 cells as a model of endocrine resistant breast cancer, the culture medium for it was devoid of phenol red, and FBS was charcoal-dextran stripped to remove estrogen. ${ }^{32}$

In Vitro Cell Uptake Studies-Cell uptake of dyes 5-8 was assessed by measuring comparative fluorescence intensity of each dye at various concentrations in a time dependent manner. The cells were plated in well plates and incubated for 2 days to attain about 80-90\% confluence; the medium from each well was removed and fresh medium added along with each individual dye at various concentrations in triplicate. For time dependent studies the same plates were replicated for various time points of each dye incubation. Similar cell uptake studies were performed for FTS-dye conjugate 11. The fluorescence intensity of 
each well from whole plate was measured by Li-COR, and the intensity data was normalized to protein content of each cell as measured by standard Bradford assay using the reagent from Bio-Rad (Hercules, CA). The data was processed with Prism Graphpad software (version 5, GraphPad Software Inc., La Jolla, CA).

Breast Cancer Xenograft Mouse Model-A breast tumor xenograft model was used for in vivo studies. Female athymic mice (3-4 weeks old) were obtained from Charles River Laboratory (Wilmington, MA). All animal in vivo studies were carried out in compliance with University of Virginia Animal Study Committee's requirements for the care and use of laboratory animals in research. The mice were handled and processed according to current guidelines of National Institutes of Health Model Procedure of Animal Care and Use. Five million MCF-7 cells harvested from cell culture were suspended in Matrigel (BD Biosciences) and were inoculated into the mammary gland fat pad of ovariectomized athymic mice as reported previously. ${ }^{31}$ The mice were implanted with silastic capsule implants containing a mixture of $17-\beta$-estradiol and cholesterol for tumor growth at a ratio of 1:3, which provided $\sim 80 \mathrm{pg} / \mathrm{mL}$ of plasma $17-\beta$-estradiol. ${ }^{31}$ Tumors were allowed to grow up to $6-8$ weeks $\left(\sim 150 \mathrm{~mm}^{3}\right)$ prior to initiation of the in vivo studies. ${ }^{33}$

In Vivo NIRF Imaging Protocol-Mice were injected with $17 \mathrm{nmol}$ of each dye or FTSdye conjugate $\mathbf{1 1}$ individually in an assigned group intraperitoneally, and optical images were acquired at various time points as indicated. The in vivo optical imaging in the nearinfrared fluorescence (NIRF) region was performed on a Xenogen IVIS Spectrum instrument with excitation wavelength fixed at $745 \mathrm{~nm}$ while emission was observed at 820 $\mathrm{nm}$. Signal was acquired with identical illumination settings (autoexposure, medium binning, $F$-stop $=2$ ) for all images. The fluorescence emission was normalized to photons per second per centimeter squared per steradian $\left(\mathrm{p} / \mathrm{s} / \mathrm{cm}^{2} / \mathrm{sr}\right)$. Acquired images were analyzed with Living Image 3.1 software (Caliper Life Sciences, Hopkinton, MA) and displayed at the same scale of fluorescence intensity. Mice were anesthetized with isoflurane $(2 \%)$ in anesthesia chambers prior to imaging. All in vivo NIR fluorescence images were acquired using auto exposure $(F$-stop $=2)$. Measurement ROIs were obtained from all tumors by drawing circles as available in software, and the background ROIs were recorded as the fluorescence emission from the other part of body. Fluorescence intensities were normalized by subtracting the background ROIs from the tumor measurement ROIs.

Confocal Microscopy and Image Acquisition-Confocal images of cell cultures on coverslips embedded in Petri dishes incubated with heptamethine cyanine dye, FTS-dye conjugate, and tumor tissue slices from mice bearing xenografts administered with FTS-dye conjugate were acquired with an inverted microscope with fluorescence turret set at the Cy-7 channel. At the same time, DAPI based nuclear stain imaging was obtained on the DAPI channel. The images were processed with varying intensities of fluorescence signal for optimized image.

Ex Vivo Dye Biodistribution Analysis-After acquiring NIRF images via Xenogen IVIS Spectrum imaging, the respective sets of mice were sacrificed with deep anesthesia using ketamine and xylazine overdose. All tumors along with other tissues such as muscle, 
liver, lung, heart, kidneys, muscle, and skins were isolated, rinsed with double distilled water, gently dried with tissue paper, and spread on black plate, and intensities of NIRF signal were measured via Xenogen IVIS Spectrum in a similar fashion as described for in vivo imaging. The ROIs were drawn on each organ and normalized to tumor volumes using Living Image software.

\section{Pharmacological Evaluation of Conjugate 11}

Cell Viability Studies-Cells were plated in 6-well plates at a density of 60,000 cells/well in their respective culture media. Two days after incubation at $37^{\circ} \mathrm{C}$, the cells were treated with FTS and FTS-dye conjugate $\mathbf{1 1}$ for 2-5 days. The final concentration of vehicle (ethanol or DMSO) was $0.1 \%$. At the end of treatment, cells were rinsed twice with saline. Nuclei were prepared for counting by sequential addition of $1 \mathrm{~mL}$ of HEPES- $\mathrm{MgCl}_{2}$ solution ( $0.01 \mathrm{M}$ HEPES and $1.5 \mathrm{mM} \mathrm{MgCl} 2)$ and $0.1 \mathrm{~mL}$ of ZAP solution $(0.13 \mathrm{M}$ ethylhexadecyldimethylammonium bromide in $3 \%$ glacial acetic acid (v/v), Sigma), and were counted using a Coulter counter for cell numbers. ${ }^{22,34}$

mTOR Inhibition Assays-Inhibition assays were performed by Western blot analysis as described previously. ${ }^{22}$ Briefly cells were grown to confluence in $60 \mathrm{~mm}$ dishes for individual agents and washed with cold PBS. To each dish was added $0.5 \mathrm{~mL}$ of lysis buffer (20 mM Tris, pH 7.5, $150 \mathrm{mM} \mathrm{NaCl}, 1 \mathrm{mM}$ EDTA, $1 \mathrm{mM}$ EGTA, $1 \mathrm{mM}$ sodium orthovanadate, $2.5 \mathrm{mM}$ sodium pyrophosphate, $1 \%$ Triton X-100, $1 \mathrm{mM} \beta$ glycerophosphate, $1 \mu \mathrm{g} / \mathrm{mL}$ leupeptin and aprotinin, and $1 \mathrm{mM}$ phenylmethylsulfonyl fluoride (PMSF)). The dishes were incubated on ice for $5 \mathrm{~min}$ prior to collection. Cells were then pulse sonicated and centrifuged at $14,000 \mathrm{rpm}$ for $10 \mathrm{~min}$ at $4{ }^{\circ} \mathrm{C}$ for removal of insoluble materials. The remaining cell lysates were stored at $-80^{\circ} \mathrm{C}$ until analysis. The total protein content of the lysate was first determined using a standard Bradford assay using the reagent from Bio-Rad (Hercules, CA). Fifty micrograms total protein content was loaded and separated on $10 \%$ SDS polyacrylamide gel, and then transferred to a nitrocellulose membrane for Western blotting. The membrane was probed with primary antibodies (Cell Signaling Technology, Danvers, MA) against phospho-p70S6K or total p70S6K (mTOR substrate) solution prepared in Tris-buffered saline containing 5\% BSA. The membrane was incubated with secondary antibody conjugated with horseradish peroxidase $(1: 2,000)$ washed two times prior to treatment with SuperSignal West Pico Chemiluminescent Substrate (Pierce, Rockford, IL), and the targeted protein bands were visualized by exposing the membrane to X-ray film. Bands of specific proteins were scanned and quantitated using a Molecular Dynamics scanner and ImageQuant program for intensity measurements.

\section{RESULTS}

\section{Synthesis of Dye and FTS-Dye Conjugate}

Synthesis of the hetero hepatamethine cyanine dye 5 was somewhat challenging since the procedure always resulted in a mixture of three components; the major product was always the desired hetero dye 5 ( $\sim 60-70 \%)$ as observed by TLC analysis, while two other minor products were homo heptamethine cyanine based dyes (IR-783, 6; and MHI-148, 7) (Figure 1). Three components were separable on preparative reverse phase (RP) silica column, since 
one of two minor homodimer dyes, IR-783 (6), was the most hydrophilic $\left(t_{\mathrm{R}}=0.7, \sim 10-\right.$ $15 \%)$ and eluted very fast, while the other MHI-148 (7) was the most hydrophobic $\left(t_{\mathrm{R}}=0.1\right.$, $\sim 10-15 \%$ ) and was retained on the column tightly. The desired hetero dye 5 was isolated as a single major component $(\sim 63 \%)$ of the three products by simple crystallization with $t_{\mathrm{R}}=$ 0.5 (Scheme 1). The purity of desired hetero dye 5 was confirmed by RP analytical HPLC and was observed to be $>95 \%$ pure. The RP analytical HPLC also revealed a similar pattern of retention of the three dyes. The synthesis and characterization of both IR-783 (6) and MHI-148 (7) were reported previously and were in agreement with the reported data. All three dyes exhibited similar UV-vis absorption spectra, with $\lambda_{\max }=776 \mathrm{~nm}$ for hetero dye (Supplemental Figure 1). The structure of a hetero dye 5 was further confirmed by ${ }^{1} \mathrm{H}$ NMR and mass spectroscopy $[\mathrm{M}+\mathrm{H}]^{+} \mathrm{m} / z 705.3122$ for $\mathrm{C}_{40} \mathrm{H}_{50} \mathrm{ClN}_{2} \mathrm{O}_{5} \mathrm{~S}$ (Supplemental Figure $2)$. The fluorescence spectra for hetero dye 5 were recorded with varying excitation wavelengths from 650 to $750 \mathrm{~nm}$. Maximal emission was observed when excited at $740 \mathrm{~nm}$ (Supplemental Figure 3). The extent of emission increased with the increase of dye concentration from 0.15 to $35 \mu \mathrm{M}$ without fluorescence quenching. As concentration increased proportionately fluorescence intensity was observed to be increased (Supplemental Figures 3 and 4). By measuring partitioning with NIRF in octanol-water $\log P$ values for each dye were determined. Compound 7 showed the most positive $\log P(1.35)$, and compound 5 demonstrated moderate improvement toward water solubility $(\log P, 0.49)$. Compounds 6 and 8 exhibited $\log P$ of -1.13 and -1.621 , respectively, suggesting compound 7 being the least water-soluble. The observed $\log P$ of 0.49 for hetero dye 5 indicated slight better water solubility as compared with compound 7, which has two carboxylic acid side chains, but compared with bis-sulfonic acid side chain containing dye $\mathbf{6}$, hetero dye $\mathbf{5}$ was as expected less water-soluble.

The hetero dye 5 was further chemically modified with ethanol amine linker via activated $N$ hydroxy succinate ester (through compound 9) to suppress the high reactivity of heptamethine cyanine dye with amine in buffer, yielding hetero dye alcohol $\mathbf{1 0}$ (Scheme 2). Alcohol 10 was characterized thoroughly by ${ }^{1} \mathrm{H}$ and ${ }^{13} \mathrm{C}$ NMR and mass spectroscopy [M + $\mathrm{H}]^{+} \mathrm{m} / z 748.2$ for $\mathrm{C}_{42} \mathrm{H}_{55} \mathrm{ClN}_{3} \mathrm{O}_{5} \mathrm{~S}$ (Supplemental Figure 5), and the spectra were in agreement with the assigned structure. The alcohol 10 was then conjugated with the FTS carboxyl group via activation through EDC to afford dye-FTS conjugate $\mathbf{1 1}$ as shown in Scheme 2. The conjugate 11 displayed ${ }^{1} \mathrm{H}$ and ${ }^{13} \mathrm{C}$ NMR data in agreement with the desired structure, and the chemical composition was confirmed by both positive and negative ion mass spectral data exhibiting $[\mathrm{M}+\mathrm{H}]^{+} \mathrm{m} / z 1087.2$ for $\mathrm{C}_{64} \mathrm{H}_{83} \mathrm{ClN}_{3} \mathrm{O}_{6} \mathrm{~S}$ and $[\mathrm{M}-\mathrm{H}]^{-} \mathrm{m} / z$ 1086.4 for $\mathrm{C}_{64} \mathrm{H}_{81} \mathrm{ClN}_{3} \mathrm{O}_{6} \mathrm{~S}$ respectively (Supplemental Figures 6a,b). The fluorescence spectra for compound $\mathbf{1 1}$ were similar to that of parent dye $\mathbf{5}$ (data not shown).

\section{In Vitro Uptake of Heptamethine Cyanine Dyes and FTS-Dye Conjugate by Breast Cancer Cells}

We first compared the amount of uptake of each dye by MCF-7 cells. Fluorescence intensities retained in the cells were normalized by protein content. At each testing concentration ( $1 \mathrm{nM}$ to $5 \mu \mathrm{M}$ ), fluorescence intensity of dye 5 was the highest among the four dyes followed by IR783 6, MHI-148 7, and Cy7 (8). The uptake of FTS-dye 11 was comparable to that of dye $\mathbf{5}$ (Supplemental Figure 7). 
We then performed the uptake study using LTED cells to compare the uptake of hetero dye 5 and FTS-dye 11 at the conditions of higher concentrations (3.125-25 $\mu \mathrm{M})$ and longer incubation time $(18 \mathrm{~h})$. The amount of uptake was expressed as fluorescence intensity per cell. We found that, at lower concentrations, the amounts of dye 5 and FTS-dye 11 taken by LTED cells were identical. At $25 \mu \mathrm{M}$ concentration, FTS-dye $\mathbf{1 1}$ uptake was slightly higher than dye $\mathbf{5}$ uptake but not significantly (Figure 2). In the absence of cells no fluorescence was detected in any wells incubated with either dye $\mathbf{5}$ or FTS-dye 11, indicating that nonspecific binding of the compounds to the plate was negligible. The confocal microscope images of MCF-7 cells from the uptake experiments of dye $\mathbf{5}$ and FTS-dye conjugate $\mathbf{1 1}$ indicated intracellular accumulation of compounds as shown in Supplemental Figure 8.

\section{Tumor Specific Targeting of Heptamethine Cyanine Dyes and FTS-Dye Conjugate in the in Vivo Breast Cancer Model}

The cells used in the in vitro studies are exclusively cancer cells without accompanying stroma. In the in vivo studies of breast cancer in an animal model, stroma is an added component, and it is necessary to determine the specificity of the dye uptake in these more complex tissues. Nude mice bearing MCF-7 xenografts were injected individually with four dyes $(17 \mathrm{nmol} /$ mouse, $n=3)$. NIRF images for animals were acquired at various time points postinjection. Two days after injection, the fluorescence intensity of all dyes (compounds $\mathbf{5}$, 6, and 7) except for Cy7 (8) were retained in the tumors (Supplemental Figure 9, panel B). A comparative in vivo uptake of hetero dye $\mathbf{5}$ and Cy 7 (8) is depicted as near-infrared fluorescence image (Figure 3 ). When normalized by tumor volumes, fluorescence intensity of dye 5 was about $\sim 8-, 4-$, and 2-fold high as compared with $\mathrm{Cy} 7$ (8) at 2, 5, and 8 days respectively (Figure 4) and was among the highest all four dyes tested. It is clear from the NIRF imaging data that hetero dye $\mathbf{5}$ has relatively better pharmacokinetic characteristics, the uptake peaked at about $30 \mathrm{~h}$, and $80 \%$ of fluorescence intensity disappeared 8 days after injection (Supplemental Figure 9, panel D).

In another set of mice similar in vivo imaging was performed as described above, mice were sacrificed at each time point, and tumors and organs were harvested for ex vivo NIRF imaging. Consistent with the whole body NIRF imaging, dyes 5, 6, and $\mathbf{7}$ showed relatively higher uptake than that of dye $\mathbf{8}$, and comparative organ distribution data among various tissues and tumor as observed for hetero dye $\mathbf{5}$ and Cy 7 (8) by NIRF signal intensity is presented in Figure 5. As observed in in vivo imaging, the ex vivo tissue distribution was in agreement, indicating higher fluorescence intensities in tumor as compared with other normal organ tissues. Compared to the muscle, fluorescence intensities in the tumor tissue were 8.6-fold higher for dye 5, 6.3-fold higher for dye $\mathbf{6}$, and 4.5 -fold higher for dye $\mathbf{7}$ on day 2 of injection (Supplemental Figure 9). All in all these results indicate that heptamethine cyanine dyes have specific tumor targeting characteristics and dye $\mathbf{5}$ is relatively better among the dyes tested.

\section{In Vivo NIRF Imaging for Uptake of FTS-Dye Conjugate 11 by MCF-7 Xenografts in Nude Mice}

Next, we examined tumor uptake of the FTS-dye conjugate $\mathbf{1 1}$ in the same nude mouse model. $17 \mathrm{nmol}$ of FTS-dye conjugate 11 was injected to each mouse $(n=3)$, and whole 
body NIRF images were acquired over time. As shown in Figure 6, fluorescence signals were concentrated in tumor area, indicating that FTS-dye conjugate $\mathbf{1 1}$ uptake was similar to that of dye 5. The ex vivo tumor NIRF imaging and confocal imaging of tumor section confirmed tumor specific uptake and retention of the FTS-dye conjugate 11 (Figure 7). The excised tumors from the mice injected with FTS-dye conjugate $\mathbf{1 1}$ indicated that the predominant uptake of the dye was in live growing tumor as indicated by fluorescence intensity that matched with reddish tissue while the white necrotic tissue appears to have less fluorescence signal (Supplemental Figure 10).

\section{Effects of FTS and FTS-Dye Conjugate 11 on Growth of Cancerous and Benign Breast Epithelial Cells}

The growth inhibitory effects of FTS and FTS-dye conjugate $\mathbf{1 1}$ were then evaluated in both MCF-7 and LTED cells. The cytotoxicity properties were evaluated by MTT assay of cell viability and count of cell number after a certain time of incubation. The FTS-dye conjugate 11 was observed to be more potent than FTS. FTS up to $75 \mu \mathrm{M}$ inhibits only about 70-75\% cells, while FTS-dye conjugate 11 inhibits $100 \%$ cell growth at $\sim 40 \mu \mathrm{M}$ concentration. Calculated $\mathrm{IC}_{50}$ for FTS-dye conjugate 11 was $16.8 \pm 0.5 \mu \mathrm{M}$, while that for FTS was about $51.8 \pm 1.8 \mu \mathrm{M}$ in LTED cells, suggesting about 3-fold improvements in potency (Figure 8).

Next, we compared the effect of the FTS-dye conjugate with FTS on growth of normal MCF-10A and LTED cells. Two day treatment with FTS-dye conjugate 11 completely inhibited LTED cell growth below $50 \mu \mathrm{M}$ concentration while at the same concentration the MCF-10A cells were almost 100\% viable indicating cell type specific response (Figure 9). In parallel both FTS and FTS-dye conjugate $\mathbf{1 1}$ have almost $100 \%$ cell viability at $50 \mu \mathrm{M}$ of MCF-10A cells indicating almost no cell growth inhibitory effect and supporting the notion that the conjugation with dye has minimum adverse effect on the benign breast epithelial MCF-10A cells (Figure 9).

As reported previously, the dye thus can be used as a safe carrier to target and deliver the drug molecule to cancer cells. In addition these observations suggest that LTED cells are more sensitive to FTS than MCF-10A cells and when conjugated with the dye the inhibitory effect of FTS is enhanced.

\section{mTOR Inhibition by FTS-Dye Conjugate 11}

Our previous studies demonstrated that mTOR activity is very low in MCF-10A cells, and their growth is not affected when mTOR is inhibited. In contrast, the mTOR pathway is upregulated in breast cancer cells especially when endocrine resistance is developed as in the case of LTED cells. ${ }^{22}$ To determine whether the dye conjugation retains the property of FTS as an effective mTOR inhibitor, we examined the effect of the FTS-dye conjugate 11 in vitro on mTOR activation by western analysis of phosphorylated p70S6K, a substrate of mTOR. The FTS-dye conjugate $\mathbf{1 1}$ exhibited an inhibitory effect on mTOR activity at lower concentration $(12.5 \mu \mathrm{M})$ than the FTS. FTS exerts similar mTOR inhibitory effect at $25 \mu \mathrm{M}$, at which the FTS-dye conjugate 11 does not further enhance the inhibition. These observations suggest that either FTS-dye conjugate has better affinity toward mTOR or excess FTS is delivered to suppress mTOR activity (Figure 10). 


\section{DISCUSSION}

The clinical usage of FTS is hindered by its poor pharmacokinetics even though it has exhibited low toxicity and promising anticancer properties. ${ }^{18,19,35}$ FTS is established as a known Ras inhibitor and has shown desirable anticancer activity in many cancer types that are associated with overly active mutated Ras expression that results in downstream cell signaling to promote cell growth and proliferation. ${ }^{19,36}$ One of the predominant mechanisms by which FTS acts as an anticancer agent involves perturbation in membrane integrity by inducing dislodgement of Ras protein from its anchorage domains, facilitating its rapid degradation, and thus disrupting Ras protein signaling. ${ }^{24,25}$ Thus, FTS causes a marked decline in both membrane-bound and cytosolic Ras. ${ }^{37}$ It has also been reported that FTS, through inhibition of the MAP kinase pathway, blocks the growth of a variety of human cancer cells in vitro and in vivo including pancreatic, melanoma, and colon cancers, and Merkel cell carcinomas. ${ }^{38-40}$ However, the effect of FTS on breast cancer has not been exhaustively studied in the past because of low occurrence of RAS mutation in patients prior to our report. Our studies on FTS in breast cancer cell lines resulted in discovery of two major new findings. First, FTS is a potent mTOR complex 1 (TORC1) inhibitor in breast cancer cells, and that is independent of Ras inhibition. Second, more significantly, it induces apoptosis in MCF-7 and LTED breast cancer cells. ${ }^{41}$ This anticancer mechanism of action of FTS is unique to breast cancer. The upregulation of growth factor pathways is involved in development of endocrine resistance, and the mTOR pathway is particularly important in relapsed breast cancer development. ${ }^{42}$ Therefore, discovery of a chemotherapeutic agent that targets the mTOR pathway will benefit those patients with endocrine resistant breast cancer. In light of interesting results from our lab about new pathways to inhibit tumor growth by FTS, especially in the case of relapsed endocrine resistant breast cancer, we are acutely involved in alleviating the poor bioavailability properties of FTS. Recently we have also reported that certain heptamethine cyanine dyes have special affinity toward a variety of cancer cells. These dyes have preferential uptake in several types of cell lines due to overexpression of organic anion transport peptides (OATPs). The overexpression of OATPs in breast cancer is an emerging area of research, ${ }^{43,44}$ and its role in cancer targeting has not been extensively studied. ${ }^{45}$ Considering these cancer targeting properties of heptamethine dyes, we were able to develop new dual mode PET/SPECT-NIRF diagnostic molecular imaging probes for cancer. The MHI-148 dye 7 has been utilized to deliver radio metal complexes (Cu-64 and Tc-99m) to tumor in a breast cancer mouse model.

Combining cancer targeting properties of heptamethine dye MHI-148 7 especially in mice bearing breast cancer and the limited bioavailability along with specific growth inhibition of endocrine resistant LTED breast cancer cells via mTOR inhibition of FTS, we realized that the pharmacological profile of FTS can be improved by conjugating with heptamethine cyanine dye. Further advances can be made to improve the clinical efficacy of FTS by cancer specific drug delivery. However, MHI-148 (7) is hydrophobic and less amenable to selective chemical modification of one of the two carboxylic acids, although two FTS molecules can be conjugated with one MHI-148 molecule, but the resulting bis-FTS conjugate would have been more hydrophobic and may not have suitably improved bioavailability. Dye 6 (IR 783) on the other hand is polar and more water-soluble and may be an ideal carrier for 
conjugation, but it also is a symmetrical molecule with two sulfonyl groups that cannot be selectively functionalized. Therefore, a hybrid structure including one carboxylic acid side chain and one sulfonic acid side chain as in hetero dye $\mathbf{5}$ was envisioned for FTS conjugation. In an effort to compare and evaluate the cancer targeting properties of these structurally distinct sets of four functionalized heptamethine cyanine dyes, they were screened via in vivo cancer NIRF imaging. By comparing NIRF signal intensities in tumor and overall organ biodistribution over time, it was observed that, except dye 8 (Cy 7), the other three heptamethine cyanine dyes have relatively similar in vitro and in vivo profiles, with subtle differences. The hetero dye, although it was not displaying low $\log P$ value, was still effective in the in vivo tumor targeting and accumulating in cancer cells. Dye 5 was chosen for mono FTS conjugation because of the ease of chemical modification and improved water solubility as compared with MHI-148 7. As shown in Figures 2 through 5, hetero dye $\mathbf{5}$ appeared to be exhibiting desired cancer cell targeting and tumor imaging properties.

The small molecule heptamethine dye is particularly attractive when compared with other delivery systems such as liposomes, nano particles, or antibody conjugation due to well characterized structure for optimizing pharmacological parameters, especially dosing and bioavailability. In addition to a well-defined structure, the heptamethine dye conjugate would also possess diagnostic abilities via NIRF imaging to monitor the progression of treatment. The dye $\mathbf{5}$ was first linked with an appropriate linker to conjugate with FTS as shown in Scheme 2. The conjugate was then thoroughly characterized for structural integrity and analyzed for purity by HPLC. The pure compound was tested against FTS in both cancer (MCF-7/LTED) and noncancer MCF-10A cell lines. Indeed the potency of conjugate was observed to be improved 3-fold (IC50 $16.8 \mu \mathrm{M}$ compared with FTS $<50 \mu \mathrm{M}$ ). The conjugate retained dose and time dependent growth inhibition profile better than FTS in MCF-7 and LETD cells with almost no growth inhibition in benign MCF-10A breast epithelial cells (Figure 9), and it also inhibited mTOR as shown by reduced phosphorylation of p70S6K at lower concentration than FTS as reported previously (Figure 10). In addition, confocal imaging with near-infrared channel demonstrated that both MCF-7 cells (in vitro) (Supplemental Figure 8) and ex vivo tumor slices obtained from mice injected with the FTS-dye conjugate (11) (Figure 7) have intracellular presence of dye. As shown in Figure $7 \mathrm{~A}$, the dye appeared to be present mostly in live cells and not in the necrotic tissue, suggesting the active transport of the dye in live cancer cells. These observations indeed support the notion that hetero dye is responsible for carrying FTS to the intracellular compartment of cancer cells and the pharmacological profile of FTS is improved, however it remained to be seen whether FTS is released inside the cell from the conjugate for biological action or the conjugate $\mathbf{1 1}$ as is responsible for improved potency. Numerous attempts were failed to quantify FTS released inside the LTED cells. However, indirect analysis of FTSdye conjugate and its alcohol precursor 10 (especially monitored at $750 \mathrm{~nm}$ ) revealed that only about 5-10\% of precursor alcohol was observable and most of conjugate was intact in the extracts over time (see Supplemental Figure 11). Further demonstration of cancer targeting and diagnostics of FTS-dye conjugate 11, in the preliminary studies, was given to mice bearing MCF-7 xenografts for the purpose of visualizing in vivo distribution as shown in Figure 6. Indeed the FTS-dye conjugate $\mathbf{1 1}$ was observed to accumulate in tumor by in 
vivo NIRF signal intensities, especially in live tissue. Many of the heptamethine cyanine dyes appear to be safe for animal consumption, however, for therapeutic efficacy studies, a huge amount of dye will be required to be administered and, hence, its toxicity must be evaluated prior to its application as carrier. ${ }^{12,46,47}$ Studies on the efficacy of dye conjugate 11 in comparison with FTS in mice bearing endocrine resistant breast cancer are underway and will be reported elsewhere.

In conclusion, FTS has exhibited the potential to be an attractive chemotherapeutic agent against endocrine resistance breast cancer, but because of its poor bioavailability and moderate potency it may face hurdles in clinical development. By conjugating with the heptamethine cyanine dye, not only can the bioavailabilty of FTS be improved but also it may be selectively delivered to intracellular compartments of cancer cells for improving its efficacy. We successfully synthesized the FTS-dye conjugate $\mathbf{1 1}$ with improved potency for cancer specific drug delivery. The in vitro properties and in vivo near-infrared imaging of compound $\mathbf{1 1}$ indicated that it may have a superior pharmacological profile for endocrine resistance LTED breast cancer by targeting intracellular mTOR signaling. In addition, in the present work, we demonstrated that FTS-dye conjugate $\mathbf{1 1}$ targets tumor in vivo by NIRF imaging, however, it remains to be seen if these improved properties are translated into actual suppression of tumor. More studies are needed to confirm the improvement in efficacy and advance it to preclinical evaluation.

\section{Supplementary Material}

Refer to Web version on PubMed Central for supplementary material.

\section{Acknowledgments}

This research was supported by grant funding (\#207-11-14) from Virginia's Commonwealth Health Research Board.

\section{ABBREVIATIONS USED}

$\begin{array}{ll}\text { DMSO } & \text { dimethyl sulfoxide } \\ \text { EDC } & \text { 1-ethyl-3-(3-(dimethylamino)propyl) carbodiimide hydrochloride } \\ \text { NIRF } & \text { near-infrared fluorescence } \\ \text { IR-783 } & \begin{array}{l}\text { 3H-indolium, 2-[2-[2-chloro-3-[[1,3-dihydro-3,3-dimethyl-1-(3- } \\ \text { sulfopropyl)-2H-indol-2-ylidene]ethylidene]-1-cyclohexen-1- } \\ \text { yl]ethenyl]-3,3-dimethyl-1-(3-sulfopropyl)-, inner salt, sodium salt }\end{array} \\ \text { Cy-7 } & \begin{array}{l}\text { heptamethine cyanine 7 dye } \\ \text { OATPs }\end{array} \\ \text { OATPanic anion transporter peptides } \\ \text { PBS } & \text { organic anion transporter peptides } \\ \end{array}$



PDA photodiode array
ROI region of interest
$t_{\mathbf{R}} \quad$ retention time

\section{References}

1. Takara K, Hatakeyama H, Kibria G, Ohga N, Hida K, Harashima H. Size-controlled, dual-ligand modified liposomes that target the tumor vasculature show promise for use in drug-resistant cancer therapy. J Controlled Release. 2012; 162:225.

2. Kraft JC, Freeling JP, Wang Z, Ho RJY. Emerging Research and Clinical Development Trends of Liposome and Lipid Nanoparticle Drug Delivery Systems. J Pharm Sci. 2014; 103:29. [PubMed: 24338748]

3. Joo K-I, Xiao L, Liu S, Liu Y, Lee C-L, Conti PS, Wong MK, Li Z, Wang P. Crosslinked multilamellar liposomes for controlled delivery of anticancer drugs. Biomaterials. 2013; 34:3098. [PubMed: 23375392]

4. Allen TM, Cullis PR. Liposomal drug delivery systems: From concept to clinical applications. Adv Drug Delivery Rev. 2013; 65:36.

5. Wicki A, Witzigmann D, Balasubramanian V, Huwyler J. Nanomedicine in cancer therapy: Challenges, opportunities, and clinical applications. J Controlled Release. 2015; 200:138.

6. Mattheolabakis G, Rigas B, Constantinides PP. Nanodelivery strategies in cancer chemotherapy: biological rationale and pharmaceutical perspectives. Nanomedicine. 2012; 7:1577. [PubMed: 23148540]

7. Tarn D, Ashley CE, Xue M, Carnes EC, Zink JI, Brinker CJ. Mesoporous silica nanoparticle nanocarriers: Biofunctionality and Biocompatibility. Acc Chem Res. 2013; 46:792. [PubMed: 23387478]

8. Deng ZJ, Morton SW, Ben-Akiva E, Dreaden EC, Shopsowitz KE, Hammond PT. Layer-by-Layer nanoparticles for systemic codelivery of an anticancer drug and siRNA for Potential Triple-Negative Breast Cancer Treatment. ACS Nano. 2013; 7:9571. [PubMed: 24144228]

9. Warram JM, de Boer E, Sorace AG, Chung TK, Kim H, Pleijhuis RG, van Dam GM, Rosenthal EL. Antibody-based imaging strategies for cancer. Cancer Metastasis Rev. 2014; 33:809. [PubMed: 24913898]

10. Alyautdin R, Khalin I, Nafeeza MI, Haron MH, Kuznetsov D. Nanoscale drug delivery systems and the blood-brain barrier. Int J Nanomed. 2014; 9:795.

11. Park K. Facing the Truth about nanotechnology in drug delivery. ACS Nano. 2013; 7:7442. [PubMed: 24490875]

12. Yang X, Shi C, Tong R, Qian W, Zhau HE, Wang R, Zhu G, Cheng J, Yang VW, Cheng T, Henary M, Strekowski L, Chung LWK. Near IR heptamethine cyanine dye-mediated cancer imaging. Clin Cancer Res. 2010; 16:2833. [PubMed: 20410058]

13. Wu JB, Shao C, Li X, Hu P, Chen Y-T, Dou X, Sahu D, Li W, Harada H, Wang R, Zhau HE, Chung LWK. Hypoxia-mediated cancer imaging by a novel class of near-infrared (NIR) heptamethine cyanine dyes. Cancer Res. 2013; 73:3913. [PubMed: 23636127]

14. Zhang Y, Xiao L, Popovic K, Xie X, Chordia MD, Chung LWK, Williams MB, Yue W, Pan D. Novel cancer-targeting SPECT/NIRF dual-modality imaging probe Tc-99m-PC-1007: Synthesis and biological evaluation. Bioorg Med Chem Lett. 2013; 23:6350. [PubMed: 24125889]

15. Yuan J, Yi X, Yan F, Wang F, Qin W, Wu G, Yang X, Shao C, Chung LWK. Near-infrared fluorescence imaging of prostate cancer using heptamethine carbocyanine dyes. Mol Med Rep. 2015; 11:821. [PubMed: 25354708]

16. Wu JB, Shao C, Li X, Shi C, Li Q, Hu P, Chen Y-T, Dou X, Sahu D, Li W, Harada H, Zhang Y, Wang R, Zhau HE, Chung LWK. Near-infrared fluorescence imaging of cancer mediated by tumor hypoxia and HIFI alpha/OATPs signaling axis. Biomaterials. 2014; 35:8175. [PubMed: 24957295]

17. Shi C, Wu JB, Chu GCY, Li Q, Wang R, Zhang C, Zhang Y, Kim HL, Wang J, Zhau HE, Pan D, Chung LWK. Heptamethine carbocyanine dye-mediated near-infrared imaging of canine and 
human cancers through the HIF-1 alpha/OATPs signaling axis. Oncotarget. 2014; 5:10114. [PubMed: 25361418]

18. Laheru D, Shah P, Rajeshkumar NV, McAllister F, Taylor G, Goldsweig H, Le DT, Donehower R, Jimeno A, Linden S, Zhao M, Song D, Rudek MA, Hidalgo M. Integrated preclinical and clinical development of S-trans, trans-farnesylthiosalicylic acid (FTS, Salirasib) in pancreatic cancer. Invest New Drugs. 2012; 30:2391. [PubMed: 22547163]

19. Riely GJ, Johnson ML, Medina C, Rizvi NA, Miller VA, Kris MG, Pietanza MC, Azzoli CG, Krug LM, Pao W, Ginsberg MS. A Phase II trial of Salirasib in patients with lung adenocarcinomas with KRAS mutations. J Thorac Oncol. 2011; 6:1435. [PubMed: 21847063]

20. Bustinza-Linares E, Kurzrock R, Tsimberidou A-M. Salirasib in the treatment of pancreatic cancer. Future Oncol. 2010; 6:885. [PubMed: 20528225]

21. Ahn TS, Jeong D, Son MW, Jung H, Park S, Kim H, Bae SB, Kim HJ, Jeon Y-W, Lee MS, Baek M-J. The BRAF mutation is associated with the prognosis in colorectal cancer. J Cancer Res Clin Oncol. 2014; 140:1863. [PubMed: 24942334]

22. Yue W, Wang JP, Li YB, Fan P, Santen RJ. Farnesylthiosalicylic acid blocks mammalian target of rapamycin signaling in breast cancer cells. Int J Cancer. 2005; 117:746. [PubMed: 15957161]

23. McMahon LP, Yue W, Santen RJ, Lawrence JC. Farnesylthiosalicylic acid inhibits mammalian target of rapamycin (mTOR) activity both in cells and in vitro by promoting dissociation of the mTOR-raptor complex. Mol Endocrinol. 2005; 19:175. [PubMed: 15459249]

24. Santen RJ, Song RX, Zhang Z, Kumar R, Jeng MH, Masamura A, Lawrence J, Berstein L, Yue W. Long-term estradiol deprivation in breast cancer cells up-regulates growth factor signaling and enhances estrogen sensitivity. Endocr -Relat Cancer. 2005; 12:S61. [PubMed: 16113100]

25. Zhang X, Lu J, Huang Y, Zhao W, Chen Y, Li J, Gao X, Venkataramanan R, Sun M, Stolz DB, Zhang L, Li S. PEG-Farnesylthiosalicylate conjugate as a nanomicellar carrier for delivery of paclitaxel. Bioconjugate Chem. 2013; 24:464.

26. Chen Y, Zhang X, Lu J, Huang Y, Li J, Li S. Targeted delivery of curcumin to tumors via PEGderivatized FTS-based micellar system. AAPS J. 2014; 16:600. [PubMed: 24706375]

27. Xiao L, Zhang Y, Yue W, Xie X, Wang J-P, Chordia MD, Chung LWK, Pan D. Heptamethine cyanine based Cu-64-PET probe PC-1001 for cancer imaging: Synthesis and in vivo evaluation. Nucl Med Biol. 2013; 40:351. [PubMed: 23375364]

28. Kiessling, F., Beijer, B., Schulz, R., Semmler, W., Mier, W., Waengler, B. Dkfz Deutsches Krebsforschungszentrum Compounds useful for the at least bi-modal diagnostic imaging. Ruprecht-Karls-Universitaet-Heidelberg; Germany: 2007. p. 24

29. Fu N, Xiong YJ, Squier TC. Optimized design and synthesis of a cell-permeable biarsenical cyanine probe for imaging tagged cytosolic bacterial proteins. Bioconjugate Chem. 2013; 24:251.

30. Wojtyk JTC, Kazmaier PM, Buncel E. Modulation of the spiropyran-merocyanine reversion via metal-ion selective complexation: Trapping of the "Transient" cis-merocyanine. Chem Mater. $2001 ; 13: 2547$.

31. Yue W, Wang JP, Hamilton CJ, Demers LM, Santen RJ. In situ aromatization enhances breast tumor estradiol levels and cellular proliferation. Cancer Res. 1998; 58:927. [PubMed: 9500452]

32. Masamura S, Santner SJ, Heitjan DF, Santen RJ. Estrogen deprivation causes estradiol hypersensitivity in human breast-cancer cells. J Clin Endocrinol Metab. 1995; 80:2918. [PubMed: 7559875]

33. Yue W, Zhou DJ, Chen SA, Brodie A. A new nude-mouse model for postmenopausal breast-cancer using MCF7-cells transfected with human aromatase gene. Cancer Res. 1994; 54:5092. [PubMed: 7923123]

34. Chen C, Chan HM, Kubow S. In situ aromatization enhances breast tumor estradiol levels and cellular proliferation. J Med Food. 2007; 10:416. [PubMed: 17887934]

35. Tsimberidou AM, Moulder S, Fu S, Wen S, Naing A, Bedikian AY, Daring S, Uehara C, Ng C, Wallace M, Camacho L, Kurzrock R. Phase I clinical trial of hepatic arterial infusion of cisplatin in combination with intravenous liposomal doxorubicin in patients with advanced cancer and dominant liver involvement. Cancer Chemother Pharmacol. 2010; 66:1087. [PubMed: 20204368]

36. Tsimberidou AM, Chandhasin C, Kurzrock R. Farnesyl-transferase inhibitors: where are we now? Expert Opin. Invest Drugs. 2010; 19:1569. 
37. Haklai R, Weisz MG, Elad G, Paz A, Marciano D, Egozi Y, Ben-Baruch G, Kloog Y. Dislodgment and accelerated degradation of Ras. Biochemistry. 1998; 37:1306. [PubMed: 9477957]

38. Jansen B, Heere-Ress E, Schlagbauer-Wadl H, Halaschek-Wiener J, Waltering S, Moll I, Pehamberger H, Marciano D, Kloog Y, Wolff K. Farnesylthiosalicylic acid inhibits the growth of human Merkel cell carcinoma in SCID mice. J Mol Med. 1999; 77:792. [PubMed: 10619439]

39. Jansen B, Schlagbauer-Wadl H, Kahr H, Heere-Ress E, Mayer BX, Eichler HG, Pehamberger H, Gana-Weisz M, Ben-David E, Kloog Y, Wolff K. Novel Ras antagonist blocks human melanoma growth. Proc Natl Acad Sci U S A. 1999; 96:14019. [PubMed: 10570191]

40. Halaschek-Wiener J, Wacheck V, Schlagbauer-Wadl H, Wolff K, Kloog Y, Jansen B. A novel Ras antagonist regulates both oncogenic Ras and the tumor suppressor p53 in colon cancer cells. Mol Med. 2000; 6:693. [PubMed: 11055588]

41. Charette N, De Saeger C, Lannoy V, Horsmans Y, Leclercq I, Starkel P. Salirasib inhibits the growth of hepatocarcinoma cell lines in vitro and tumor growth in vivo through ras and mTOR inhibition. Mol Cancer. 2010; 9:256. [PubMed: 20860815]

42. Musgrove EA, Sutherland RL. Biological determinants of endocrine resistance in breast cancer. Nat Rev Cancer. 2009; 9:631. [PubMed: 19701242]

43. Banerjee N, Miller N, Allen C, Bendayan R. Expression of membrane transporters and metabolic enzymes involved in estrone-3-sulphate disposition in human breast tumor tissues. Breast Cancer Res Treat. 2014; 145:647. [PubMed: 24831777]

44. Hashimoto Y, Tatsumi S, Takeda R, Naka A, Ogane N, Kameda Y, Kawachi K, Shimizu S, Sakai M, Kamoshida S. Expression of organic anion-transporting polypeptide 1A2 and organic cation transporter 6 as a predictor of pathologic response to neoadjuvant chemotherapy in triple negative breast cancer. Breast Cancer Res Treat. 2014; 145:101. [PubMed: 24671357]

45. Liu T, Li Q. Organic anion-transporting polypeptides: a novel approach for cancer therapy. J Drug Targeting. 2014; 22:14.

46. Lim SY, Hong KH, Kim DI, Kwon H, Kim HJ. Tunable Heptamethine-Azo Dye Conjugate as an NIR Fluorescent Probe for the Selective Detection of Mitochondrial Glutathione over Cysteine and Homocysteine. J Am Chem Soc. 2014; 136:7018. [PubMed: 24754635]

47. Lu CF, Das S, Magut PKS, Li M, El-Zahab B, Warner IM. Irradiation Induced Fluorescence Enhancement in PEGylated Cyanine-Based NIR Nano- and Mesoscale GUMBOS. Langmuir. 2012; 28:14415. [PubMed: 22957476] 

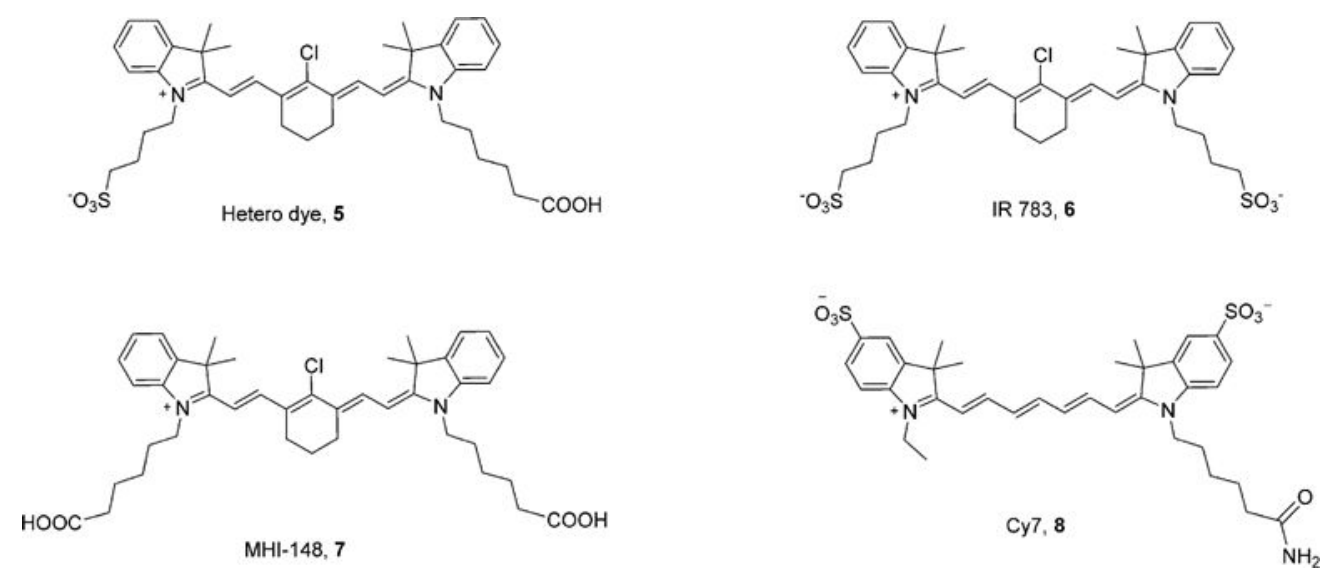

Figure 1.

Four distinctly functionalized heptamethine cyanine dyes selected for tumor targeting. 


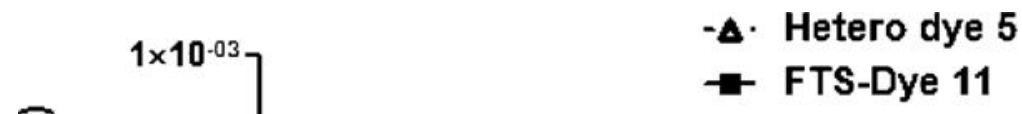

$\widetilde{0}$

+1 1 $1 \times 10^{-03}-1$

동

$\stackrel{\Phi}{\underline{E}}$

产

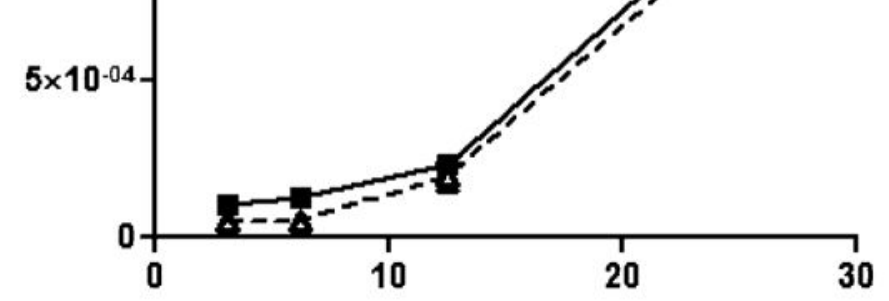

Concentration $\mu \mathrm{M}$

Figure 2.

Comparative concentration dependent uptake of hetero dye $\mathbf{5}$ and FTS-dye conjugate $\mathbf{1 1}$ in LTED cells. 


\section{Hetero dye, $\mathbf{5}$}
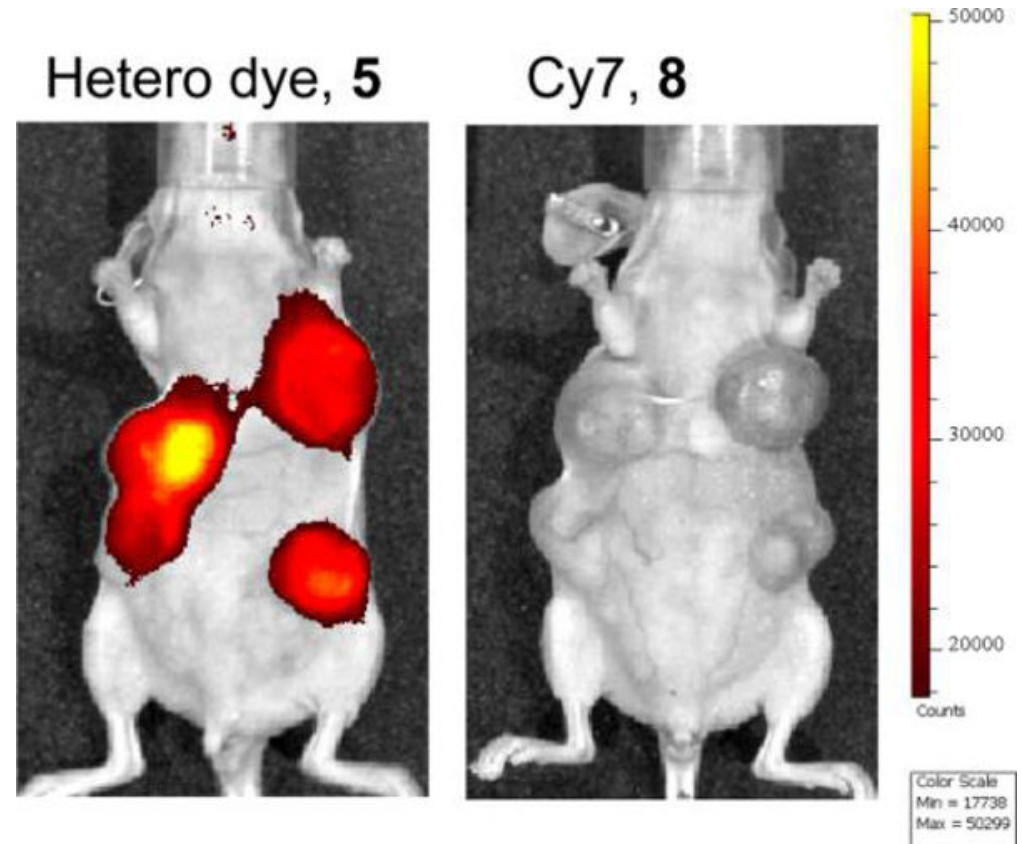

Figure 3.

In vivo evaluation of the hetero dye $\mathbf{5}$ and cyanine $\mathbf{7}$ for cancer specific targeting by NIRF imaging (excitation at $740 \mathrm{~nm}$, observed emission at $820 \mathrm{~nm}$ ) 2 days postinjection. 

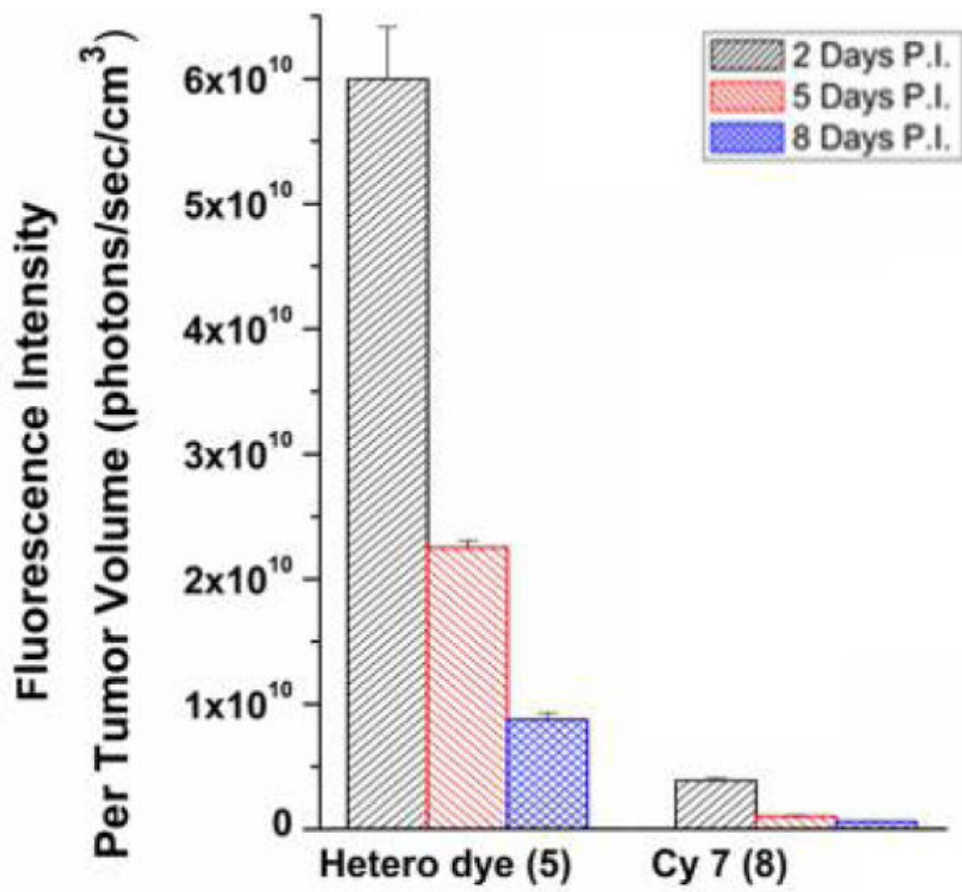

Figure 4.

Distribution of dyes $\mathbf{5}$ and $\mathbf{7}$ with time as measured by fluorescence intensities normalized to tumor volume. 


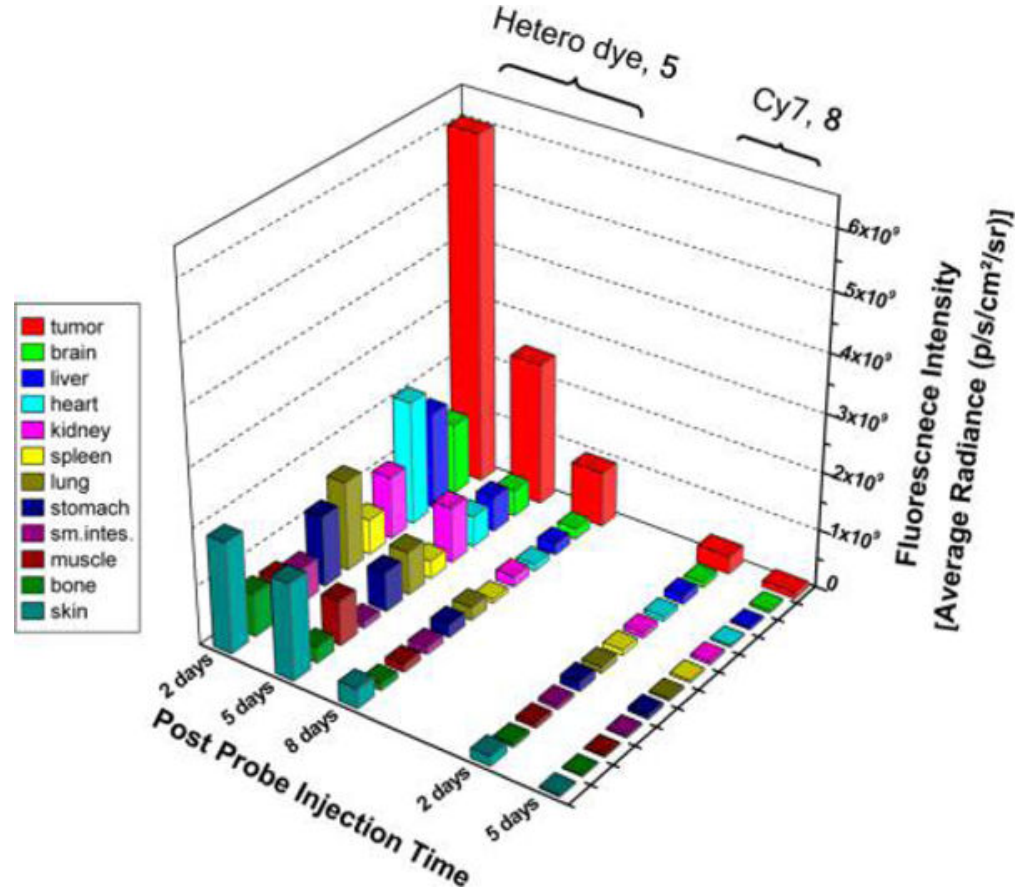

Figure 5.

Overall organ distribution profile of dyes $\mathbf{5}$ and $\mathbf{7}$ with time as measured by fluorescence intensities normalized to tumor volume. 

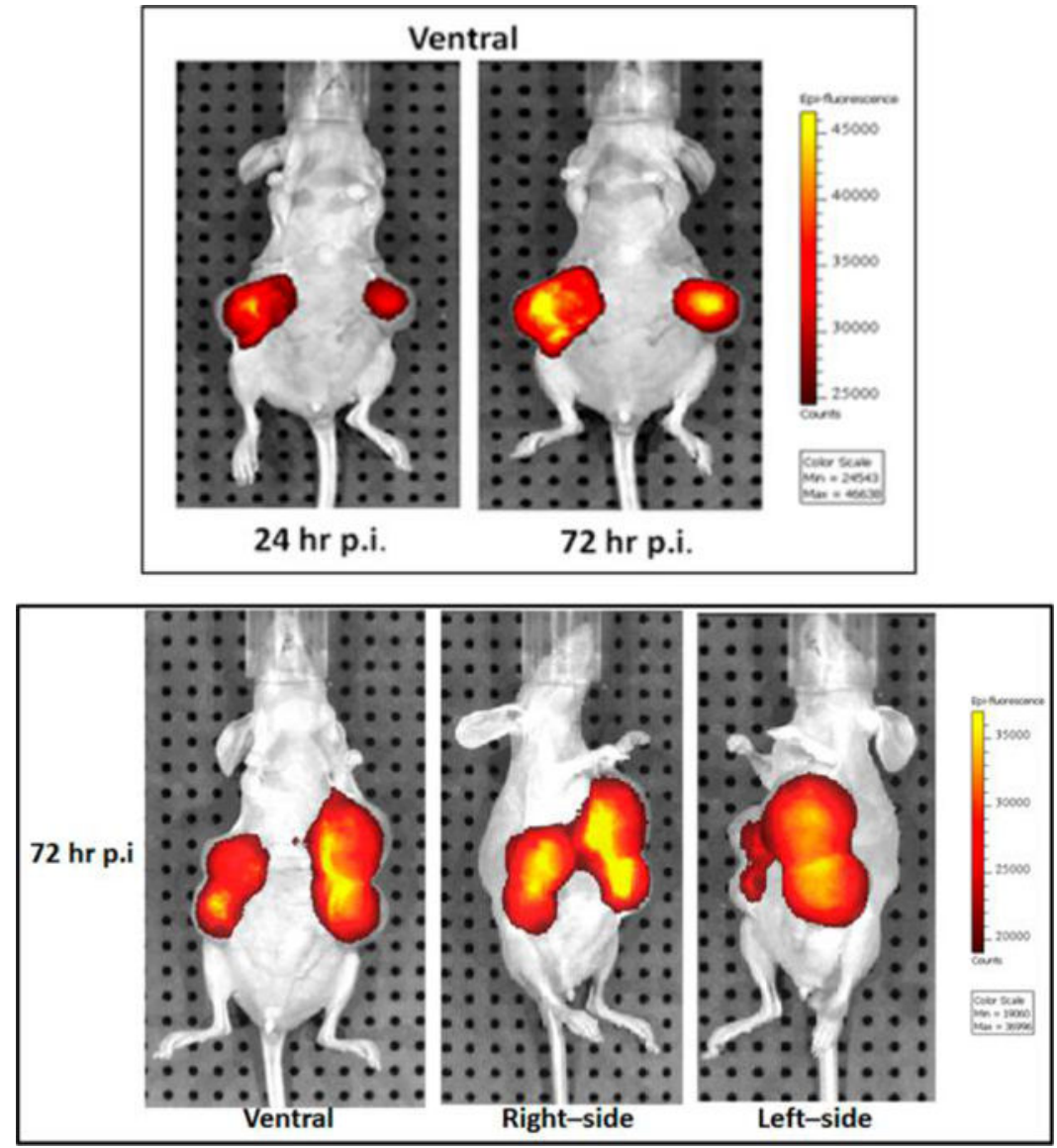

Figure 6.

NIRF imaging of mice bearing MCF-7 breast tumors upon injection of FTS-dye conjugate $11(17 \mathrm{nM})$ in a time dependent manner suggesting tumor specific targeting and accumulation. Two separate mice with two and four xenografts in various positions are shown. 

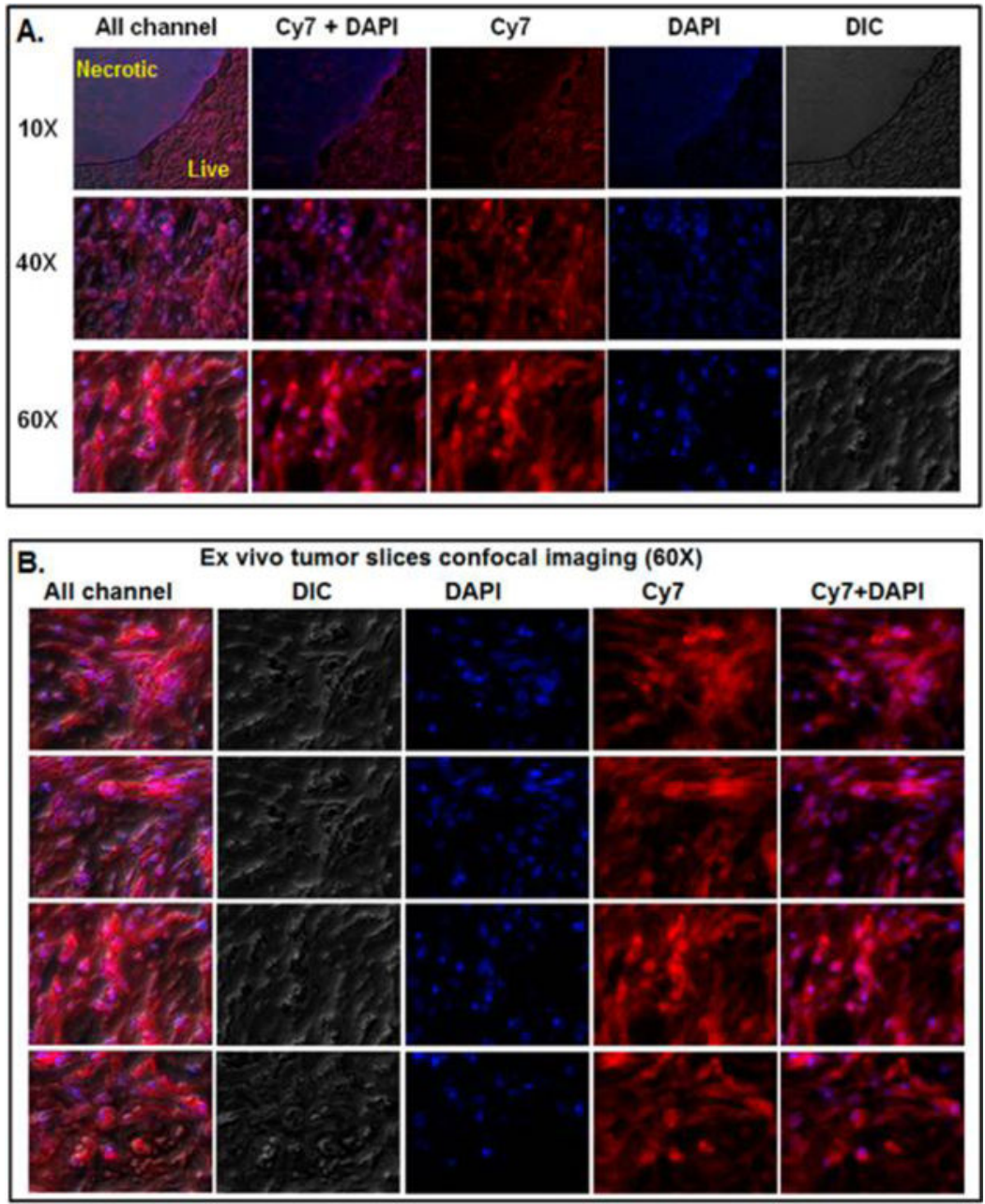

Figure 7.

Representative inverted confocal microscopic imaging of tumor slice $(10 \mu \mathrm{m})$ harvested from mice bearing MCF-7 xenograft injected with hetero dye $\mathbf{5}$ using three channels. DIC, visible, DAPI (Ex $355 \mathrm{~nm}$ ), blue for nuclear, and Cy7 (Ex $636 \mathrm{~nm}$ ), red for near-infrared for FTS-dye conjugate 11. (A) Live tumor and necrotic tissue and (B) various slices of live tumors at $60 \times$ zoom level. 
A.

Figure 8.

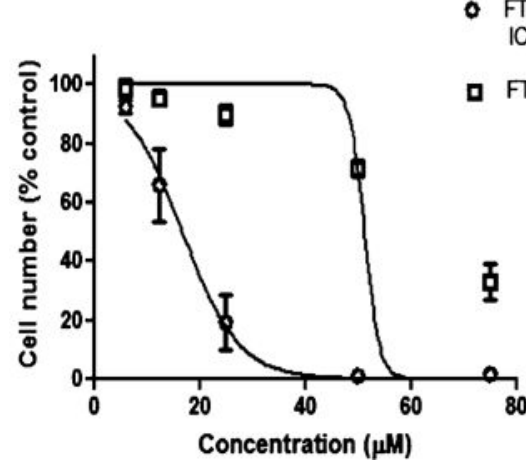

B.

FTS-Dye Conjugate $I_{50}=16.8$

FTS, $I_{50}=\sim 51.3$

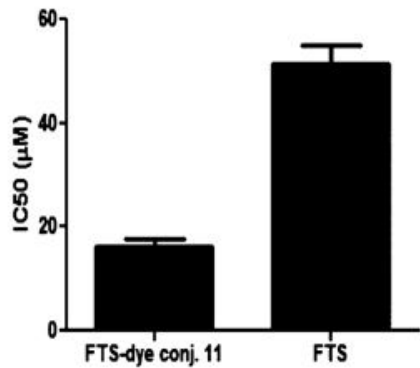

Comparative cytotoxicity assays of FTS with FTS conjugate 11 in LTED cells. Doseresponse curve for FTS and FTS-dye conjugate 11 (A). Relative $\mathrm{IC}_{50}$ values (B). 


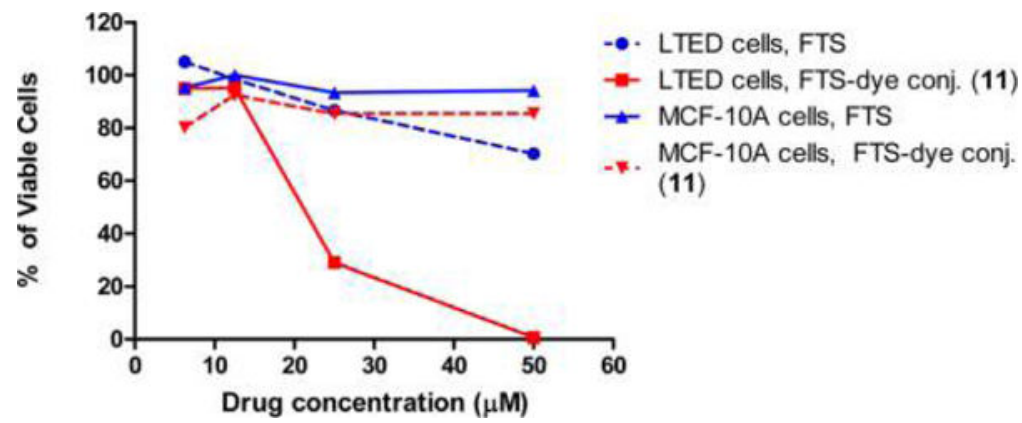

Figure 9.

Inhibition effects of FTS-dye conjugate $\mathbf{1 1}$ on endocrine therapy resistant LTED cells and benign MCF-10A cells. The assays are repeated three separate times normalized to $100 \%$ cell viability and plotted against conjugate $\mathbf{1 1}$. 


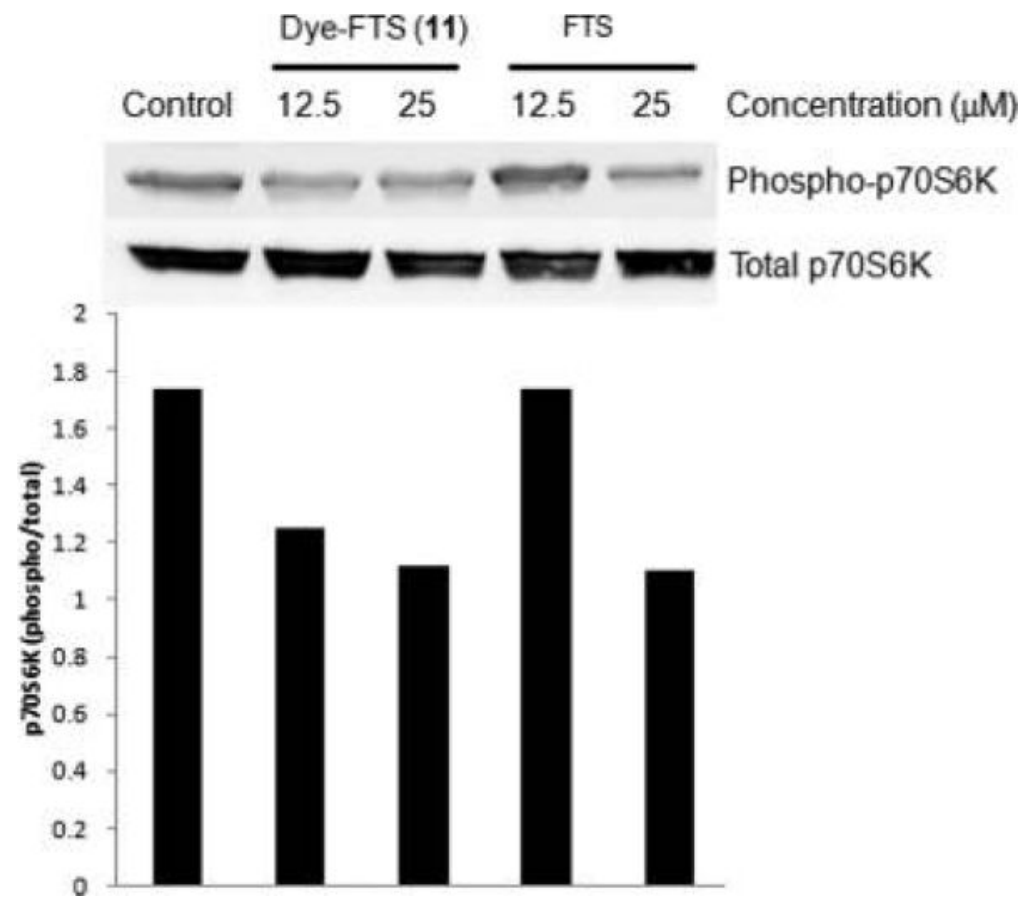

Figure 10.

Inhibition of FTS-dye conjugate 11 on mTOR expression in comparison with FTS and control (DMSO) as shown by Western blot analysis. 

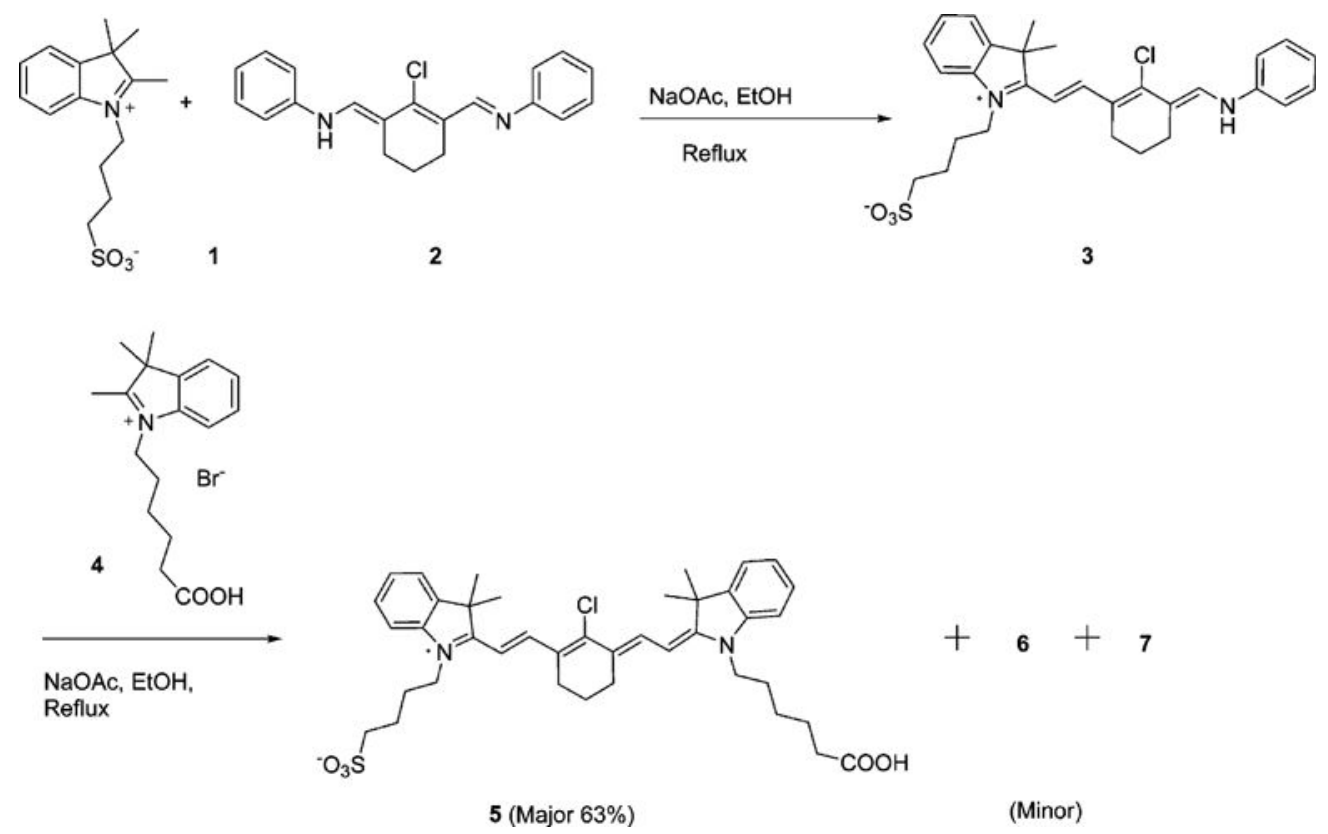

Scheme 1.

Synthesis of Hetero Heptamethine Cyanine Dyes 5, 6, and 7 

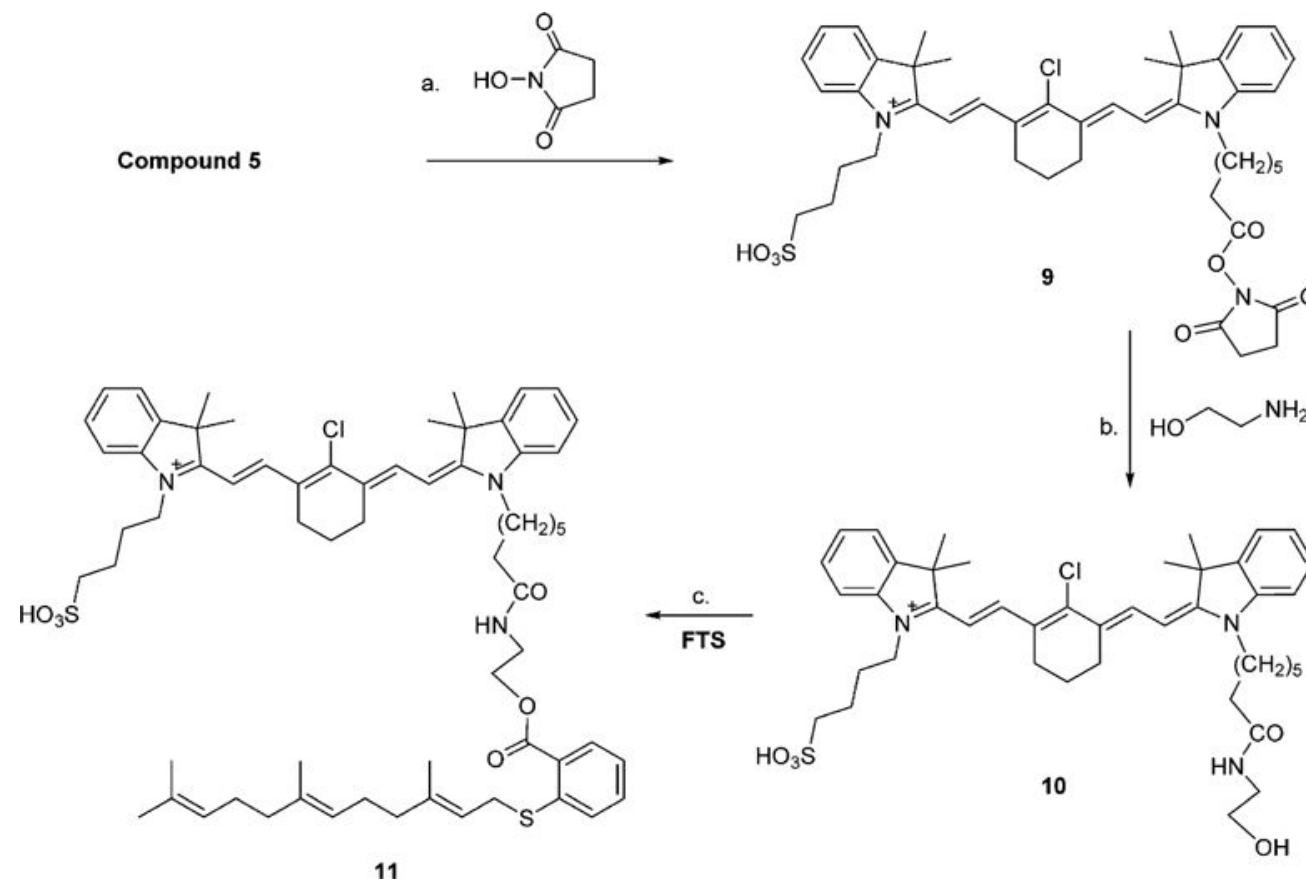

9
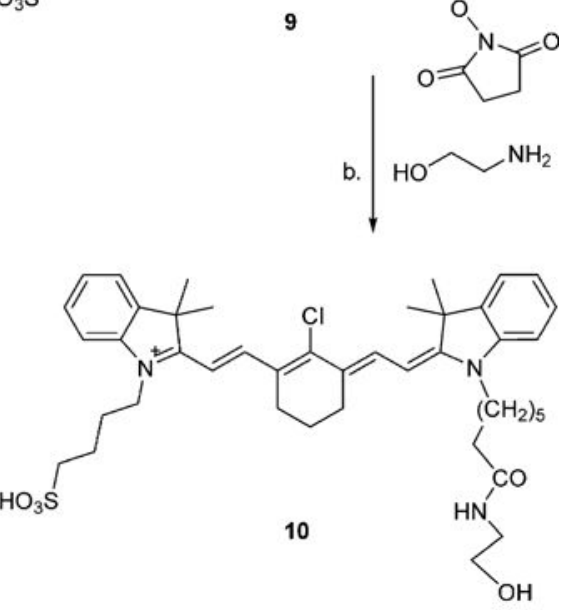

Scheme 2.

Synthesis of FTS-Hetero Heptamethine Cyanine Dye Conjugate 11

Mol Pharm. Author manuscript; available in PMC 2018 February 16. 